\title{
Hydrodynamic variability in the Southern Bight of the North Sea in response to typical atmospheric and tidal regimes. Benefit of using a high resolution model
}

\author{
Evgeny Ivanov ${ }^{\mathrm{a}, *}$, Arthur Capet ${ }^{\mathrm{a}}$, Alexander Barth ${ }^{\mathrm{b}}$, Eric J.M. Delhez ${ }^{\mathrm{c}}$, Karline Soetaert ${ }^{\mathrm{d}}$, \\ Marilaure Grégoire ${ }^{a}$
}

\author{
a MAST-AGO, University of Liège, Liège, Belgium \\ ${ }^{\mathrm{b}}$ GHER-AGO, University of Liège, Liège, Belgium \\ c A\&M, University of Liège, Liège, Belgium \\ ${ }^{\mathrm{d}}$ EDS, Royal Netherlands Institute of Sea Research and Utrecht University, Netherlands
}

\section{A R T I C L E I N F O}

\section{Keywords:}

Hydrodynamic variability

Ocean modeling

Belgian Coastal Zone

Southern Bight of the North Sea

\begin{abstract}
A B S T R A C T
In this paper, the hydrodynamics of the Southern Bight of the North Sea (SBNS) and in particular, the Belgian Coastal Zone (BCZ) is investigated on daily to seasonal time scales using a high resolution hydrodynamical model. The Regional Ocean Modeling System (ROMS) is implemented over the SBNS with $5 \mathrm{~km}$ resolution and downscaled at $1 \mathrm{~km}$ resolution over the BCZ in a two-way nesting configuration run over a three years period (i.e. 2006-2008). The benefit of using a high resolution model over the BCZ is assessed through an extensive comparison of model results with data from satellite and in-situ fixed platforms as well as reference products available for the region. The validation exercise and the results analysis are conducted with a particular focus on hydrodynamic features that are expected to impact the sediment transport. We find that despite the validation procedure does not allow to clearly demonstrate better performance of the high resolution model compared to the coarse resolution model in terms of overtidal circulation, sea surface temperature (SST) and salinity (SSS), the high resolution model resolves additional details in the variability of residual circulation and Scheldt salinity plume dynamics. The analysis of the response of the simulated hydrodynamics to atmospheric regimes for neap and spring tide highlights the major role played by the wind direction on the averaged currents and plume extension. The strongest currents and minimum plume extension are obtained under southwestern winds and neap tide while when northeastern winds prevail, the plume extension is at its maximum and the circulation is the weakest. We show that while neap tides allow the establishment of streamlined circulation, the spring tides induce more turbulent circulation which can favor the retention of transported elements. This latter property could not be resolved with the $5 \mathrm{~km}$ resolution model.
\end{abstract}

\section{Introduction}

In recent decades, the Southern Bight of the North Sea (SBNS) and, in particular, the Belgian Coastal Zone (BCZ), have been affected by an increasing number of human activities (Breton and Moe, 2009; Kaldellis and Kapsali, 2013). More specifically, aggregate extraction and dumping, and installation of offshore wind farms (OWF) have affected seafloor composition and sediment grain size distribution with potential consequences for benthic biodiversity and biogeochemical cycles that are hardly known. Offshore wind farms affect local biodiversity (De Mesel et al., 2015), and through accumulation of filtering epifauna impacts on the regional productivity (Slavik et al., 2018); with regional impact on pelagic ecosystems (Floeter et al., 2017) and biogeochemistry (Van der Molen et al., 2014). While the impact of OWF on the ecosystem starts to be documented at the scale of a single windmill or that of a wind farm (De Mesel et al., 2013), the multi-farms impact is still uncertain and debated (e.g. Van den Eynde et al., 2013, Degraer et al., 2018).

Assessing the impact of human activities at the scale of the ecosystem is a necessary requirement for managing these activities, to support the implementation of the EU Marine Strategy Framework Directive (MSFD) aiming at preserving the Good Environmental Status (GES) of marine waters, and more generally, to support implementation of the Blue Growth strategy at the base of a sustainable economic development (Costanza et al., 1999). It requires the development of sound tools capable to scale up the local impact inferred from observations to those large scale consequences in which managers are interested. For human

\footnotetext{
* Correspondence to: MAST-AGO, University of Liège, Bât B5a, Allée du 6 Août 19, 4000 Liège, Belgium.

E-mail address: evgeny.ivanov@uliege.be (E. Ivanov).
} 
activities that alter the sediment structure these tools should link the hydrodynamics, sediment transport, biodiversity and biogeochemistry. This challenge is at the core of the BELSPO (BELgian Science Policy Office) FaCE-It (Functional biodiversity in a Changing sedimentary Environment: Implications for biogeochemistry and food webs in a managerial setting) project that aims at understanding the impact of sediment fining and hardening on the benthic ecosystem functioning (i.e. biogeochemical cycling and food webs) and its implication at local and regional scale with a focus on the BCZ. The first requirement in that regard is to resolve the variability of the BCZ hydrodynamics at the relevant scales and to delineate the regional spatial imprint of local perturbations.

During the last two decades, significant efforts have been spent on the modeling of the SBNS and North-Western European Shelf (NWES) using hydrodynamic models (e.g. Delhez, 1996; Delhez et al., 2004 and references therein; Lacroix et al., 2004; Holt et al., 2005; Hashemi et al., 2015), later coupled with ecosystem and biogeochemical models (e.g. Moll and Radach, 2003; Pohlmann, 2006; Allen et al., 2007b; Lacroix et al., 2007; Los et al., 2008; Pätsch et al., 2017 and references therein) and sediment transport models (e.g. Fettweis and Van den Eynde, 2003; Mercier and Delhez, 2007). All these models are targeting the simulations and understanding of the NWES and/or SBNS dynamics at seasonal and, sometimes, interannual scales. So far very few initiatives have targeted the modeling and analysis of the BCZ hydrodynamics, except for Luyten et al. (2003), who used the COHERENS model of the North Sea to simulate and analyze the hydrodynamics specifically for the region of the BCZ with a horizontal resolution of $7.3 \mathrm{~km}$. The scaling-up of wind farm and dredging activities impact combined with the particularities of the BCZ (e.g. strong tidal currents, complex bathymetry, river plume dynamics) however, requires much higher resolution to adequately simulate coastal dynamics. A sound representation of sediment erosion, deposition and transport processes can only be guaranteed if coastal processes governed by lateral forcing and the local non-linearities (e.g. river plume dynamics, residual and tidal currents interactions and bottom shear stress) are satisfactorily represented. Also, the necessity to assess the long-term large scale impact that matters for policy development, requires the development of models that can be applied at multi-annual scales, involve a sufficiently large domain (i.e. beyond the BCZ) and yet provide enough spatial resolution in certain specific areas.

Here we implement the Regional Ocean Modeling System (ROMS) model, that is part of the Coupled Ocean-Atmosphere-Wave-Sediment Transport (COAWST) model (Warner et al., 2010). The COAWST framework offers specific modules needed to address our objectives, like the sediment transport module and wave model. In this paper, we only focus on the ROMS model, that solves the hydrodynamics of the SBNS. The BCZ is covered by a $1-\mathrm{km}$ model (defined here below as the high resolution model and noted HR) two-way nested in a $5-\mathrm{km}$ model (defined here below as the coarse resolution model and noted $\mathrm{CR}$ ) covering the SBNS. We will describe the implementation, validation and results of the ROMS hydrodynamical model targeting hydrodynamical processes that are expected to impact simulated sediment transport, erosion and deposition such as the residual and tidal circulation, transport through the straits (i.e. dominant input of SPM into the region by Mercier and Delhez, 2007), plume dynamics as well as the impact on them of weather and tidal patterns. Model performances are assessed by comparing the simulations with in-situ and satellite observations comparing the skills of the CR and HR models in order to highlight variables and processes that benefit from an increased resolution. However, although we use all the data collected for the area, data availability is often limited in space and time for demonstrating the potential improvements of using a HR configuration. Also, in addition to a classic model-data comparison, we assess the potential benefits of using a HR model by comparing the variability of selected features in time and space in response to atmospheric and tidal forcing. This allows to evidence aspects of this variability that could only be unveiled by the use of a high resolution model.
The paper is organized as follows. Section 2 provides an insight into the main hydrodynamic features of the SBNS. Section 3 describes the model formulation and its implementation over the SBNS including a downscaling approach for the BCZ. Section 4 provides a quantitative and qualitative comparison of simulated fields with observations, identifies processes that are better represented by the HR model compared to the CR model, but also aspects those for which the high resolution does not induce substantial enhancement of the model skill metrics. Section 5 analyzes the variability of the BCZ hydrodynamics in response to dominant drivers and assesses the CR and HR capacity to resolve features of this variability. Section 6 gives a conclusion and perspectives.

\section{Physical-geographical characteristics of the SBNS}

The SBNS is a part of the NWES, comprising the north-west European seas (e.g. North, Celtic, Ireland, Malin and Hebrides Seas, the English Channel, Skagerrak and Kattegat). The SBNS $\left(51^{\circ}-54^{\circ} \mathrm{N}\right)$ lies between Belgium and the Netherlands on the east and Great Britain on the west and is characterized by three zones: the UK coastal zone, the continental coastal zone, and the central water between them, with significant differences in turbidity (Laevastu, 1963). It is connected to the English Channel (EC) through the narrow ( $\sim 33 \mathrm{~km}$ width) Pas de Calais in the south and to the central North Sea in the north. The hydrodynamics of the NWES is under the dominant influence of the Atlantic Ocean, which penetrates it as a high salinity-tongue with waves, tides and currents. Macroscale circulation of the NWES is globally directed to the northeast on the outer shelf (Delhez, 1996). On the inner shelf, a cyclonic circulation develops and its intensity varies in relation to largescale atmospheric oscillations (e.g. Sündermann and Pohlmann, 2011). The range of this interannual variability is less marked in the SBNS, where a northeast flow dominates. Tides originate from the Atlantic and their propagation is essentially conditioned by the bathymetry and the irregular coastline of the region. The dominant constituents are semidiurnal, with the principal lunar (M2) component representing roughly $70 \%$ of the whole tidal range, followed by the principal solar (S2) and larger lunar elliptic (N2) components. Besides tides, the hydrodynamics of the SBNS is conditioned by winds and significant rivers inputs (i.e. the Rhine, including the Maas discharge and the Scheldt from the continent side, and the Thames from Great Britain), bringing together around $\sim 3.2 * 10^{-3} \mathrm{~Sv}$, and by inputs of salty waters coming from the North Atlantic as part of the Gulf Stream with an inflow of 0.1 Sv entering the SBNS through the English Channel. While the Thames impact is rather local and does not affect the BCZ, Rhine, Maas and Scheldt discharges combine to form a continuous freshwater plume, extending in both the southern and northern directions and creating vertically stratified areas. In the center of the SBNS, air temperature ranges over the year from 4 to $20{ }^{\circ} \mathrm{C}$, but can exceed these values at the Regions of Freshwater Influence (ROFIs). Salinity is roughly 34, except for ROFIs. The sediment dynamics is influenced by a range of interrelated processes such as meteorological and hydrodynamic conditions, turbulence, resuspension and deposition, extension of river plume and haline mixing along its boundaries, thermal dynamics and biological activity.

\section{Modeling system}

In this section we describe the modeling framework and detail its implementation in the SBNS and BCZ. We then briefly discuss the nesting setup chosen for the simulations. 


\subsection{Model description}

We use the version of ROMS developed by the Rutgers University which was first introduced by Haidvogel et al. (2000). ROMS is a three-dimensional primitive equation, free-surface model based on the Reynolds averaged Navier-Stokes equations using hydrostatic and Boussinesq approximations with a split-explicit time stepping algorithm (Shchepetkin and McWilliams, 2005). ROMS solves for the free surface, velocity, temperature, salinity, turbulent kinetic energy per unit mass and uses a state equation for computing the density field from salinity, temperature and pressure. It uses a horizontal curvilinear Arakawa C-grid and vertical stretched terrain-following coordinates. It includes the continuity equation, horizontal and vertical momentum equations, the internal energy and salt budgets and the k- $\omega$ turbulence closure scheme (Warner et al., 2010). The k- $\omega$ turbulence scheme solves differential equations for the turbulent kinetic energy per unit mass $(\mathrm{k})$ and its specific rate of dissipation $(\omega)$. It has been chosen for its numerical stability and ability to solve estuarine processes (Warner et al., 2005). The MPDATA horizontal advection scheme (Smolarkiewicz and Margolin, 1998) is chosen for its consistency in solving the estuarine circulation. Horizontal advection is calculated using the 3rd-order upstream bias scheme for 3D momentum and 4th-order centered scheme for 2D momentum while the vertical advection is 4th-order centered for 3D momentum. Horizontal diffusion coefficients are $25 \mathrm{~m}^{2} / \mathrm{s}$ in the $\mathrm{CR}$ grid and $1 \mathrm{~m}^{2} / \mathrm{s}$ in the HR model. We use the wetting and drying scheme implemented in ROMS by Warner et al. (2013), which uses an approach consistent with a cell-face blocking algorithm. The method prevents outflow from a cell, when sea surface elevation in that cell is less than a critical value of $0.1 \mathrm{~m}$ (true for temporarily dry cells). The wet-dry mask is evaluated for each barotropic time step, and the dry grid cell becomes wet again, if its sea surface elevation exceeds $0.1 \mathrm{~m}$.

\subsection{Model implementation}

The model domain extends from $3^{\circ} \mathrm{W}$ to $6^{\circ} \mathrm{E}$ and from $49^{\circ} \mathrm{N}$ to $55^{\circ} \mathrm{N}$, covering the entire SBNS and the eastern part of the Eastern EC (Fig. 1a). The CR model extends from the middle of the EC in the south to the end of the SBNS in the north and has a horizontal resolution of $5 \mathrm{~km}$, whereas the HR model covers the BCZ with a grid of $1 \mathrm{~km}$. The maximum depth within the model area is $86 \mathrm{~m}$, and the minimum depth is chosen as $6 \mathrm{~m}$ for the CR grid and $2.5 \mathrm{~m}$ for the HR grid. The land-sea mask is updated for the HR domain in order to represent individual features of the shore, such as a port of KnokkeHeist or the Scheldt estuary. Over the vertical we use terrain following $\sigma$-coordinates. The grid comprises $15 \sigma$-layers with a refined resolution near the surface (less than $1 \mathrm{~m}$ ) and 1-4 m resolution at the bottom (depending on the water depth), with surface and bottom stretching parameters $\left(\theta_{s}\right.$ and $\left.\theta_{b}\right)$ of respectively 7 and 3 . An attempt to further increase the vertical resolution at the bottom $\left(\theta_{s}\right.$ and $\theta_{b}$ of respectively 3 and 7) failed because it degraded model performances in resolving the tides.

The bathymetry of the CR and HR models are built by interpolation from the GEBCO high resolution product $(1 \mathrm{~km})$ delivered by the British Oceanographic Center (IOC, 2003). Except for a relatively steep bottom at the northern part of the domain, the bathymetric gradient is small, less than $1 \mathrm{~m} / \mathrm{km}$ within the BCZ in the direction perpendicular to the coastline. However, the BCZ is characterized by a set of large bottom ripples, where the local gradient can exceed $8 \mathrm{~m} / \mathrm{km}$. Within the Scheldt estuary, the bathymetry is derived from the local highresolution product provided by the Flanders Marine Institute (VLIZ). In order to avoid formation of spurious currents, the bathymetry is then smoothed by reducing the slope parameter as in Martinho and Batteen (2006) with a threshold of 0.35 , as a good compromise between stability and realistic bathymetry.

At the lateral open sea boundaries with the central North Sea and the EC, we use the product from the Copernicus Marine Environment
Monitoring Service (CMEMS, http://marine.copernicus.eu/) physical model, covering the NWES with a horizontal resolution of $7 \mathrm{~km}$, which has $10 \mathrm{z}$-vertical levels, and is based on the NEMO ocean model. The interpolation between the CMEMS product on the ROMS grid at the boundary is made using the SCRIP library and the pyroms package (https://github.com/ESMG/pyroms). The benefits of nesting a regional model into a large-scale ocean model instead of a climatology are underlined in Barth et al. (2008a).

A radiative boundary condition is imposed for the vertical profiles of velocity, temperature and salinity (Marchesiello et al., 2001) with a nudging term acting at the boundary and over a transition zone (flow relaxation scheme) as in Barth et al. (2008b). This relaxes the ROMS model solution towards the CMEMS fields at the open boundary with a relaxation time scale of 0.1 day. The barotropic velocity uses the Flather boundary condition (Flather, 1976).

Eleven tidal constituents (M2, S2, N2, K2, K1, O1, P1, Q1, M4, MS4, MN4) are imposed at the open boundary, i.e. major and minor axis, inclination angle and phase of the tidal velocity ellipses, as well as tidal heights amplitude and phase, issued from the NWES regional product of the tidal model TPXO (Egbert et al., 2010). The discharges from the major rivers (the Seine, the Thames, the Rhine and the Maas) are imposed as point sources of momentum, temperature and salinity. The representation of the Western Scheldt is more critical due to its proximity to the BCZ. In order to allow the tidal penetration and damping in the estuary, the Scheldt (Fig. 1b) is represented as a channel and its discharge is imposed $30 \mathrm{~km}$ inshore at Terneuzen. Daily-averaged water discharges and temperatures are taken from the data archive provided by the Swedish Meteorological and Hydrological Institute (SMHI) (Lindström et al., 2010).

At the sea surface, the air-sea exchange is computed using the bulk formulations of Fairall et al. (2003) using atmospheric variables (i.e. short-wave radiation flux, air temperature, relative humidity, cloud fraction) from the 3-hourly ECMWF Era-Interim product (https://www. ecmwf.int/en/forecasts/datasets/browse-reanalysis-datasets), at a horizontal resolution of $0.125^{\circ}$ interpolated on the model grid. The vertical propagation of the short-wave radiation is described based on the Jerlov formulation for turbid waters, type 5 (Paulson and Simpson, 1977). At the bottom, we impose a logarithmic boundary layer (Warner et al., 2010) with a constant bottom roughness of $0.005 \mathrm{~m}$.

The model is initialized with 3D fields of velocities, temperature and salinity obtained from the CMEMS reanalysis products (NORTHWESTSHELF REANALYSIS PHY 004 009) and interpolated on our grids. After a transient adjustment of a few days, it is run for the period 2006-2008 with a time step of respectively $600 \mathrm{~s}$ and $120 \mathrm{~s}$ for the CR and HR models. All simulations are conducted on the NIC4 (http://www.cecihpc.be/clusters.html\#nic4) supercomputer cluster on $32 \mathrm{CPU}$ resulting in computational time $\sim 625$ times faster than real time.

\subsection{Nesting set-up}

Grid nesting is commonly used in hydrodynamic modeling to increase the resolution in a region of particular interest while using a coarser resolution over the rest of the domain so as to provide consistent boundary conditions while ensuring the feasibility of multiyear simulations. There are different ways for connecting the CR and HR models: either the CR model imposes its conditions to the HR model without any feedback (one-way or offline nesting), or the HR model feedbacks on the CR model and updates its dynamics (two-way nesting).

Here, the results of the HR model are used to update results of the CR model over the contact point layer in two-way nesting. The total water volume for the HR domain in two-way nesting simulations does not show any drift over a three year run, and varies only according to changes in the lateral and surface fluxes. This was not the case for the one-way nesting simulation, for which a steady increase of the total water volume in the HR domain could not be avoided (increase of $0.76 \%$ 


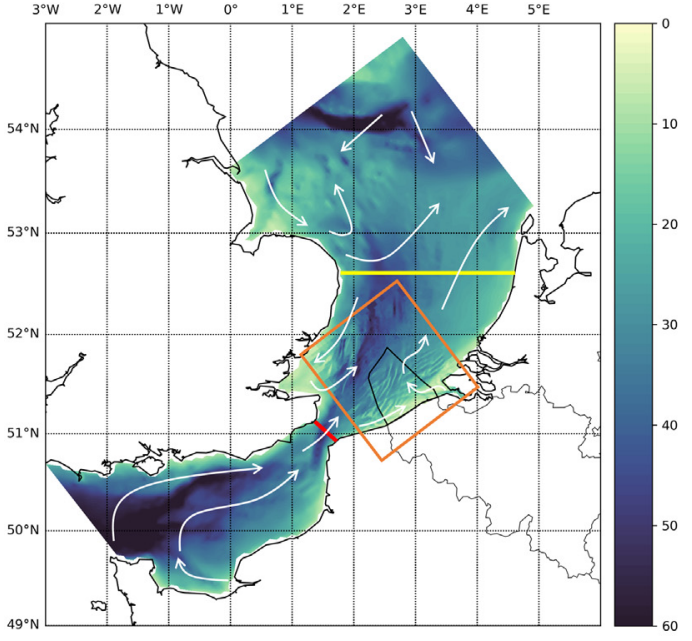

a)

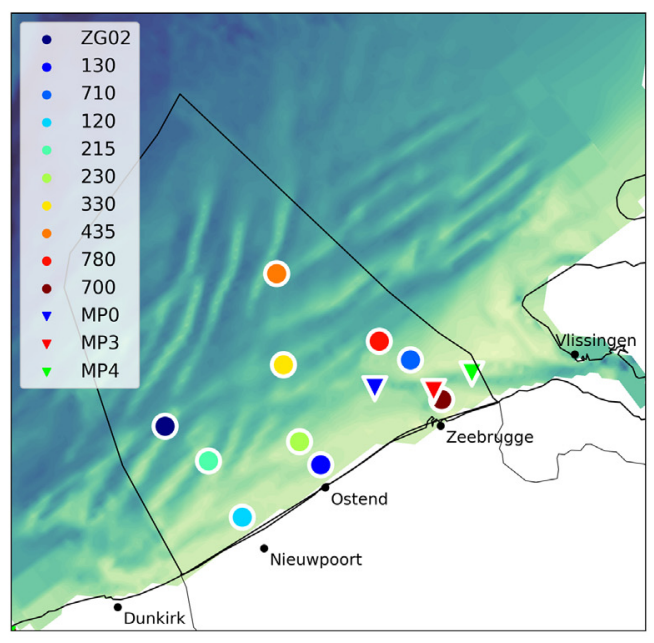

b)

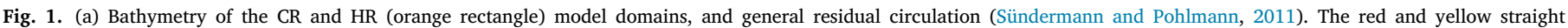

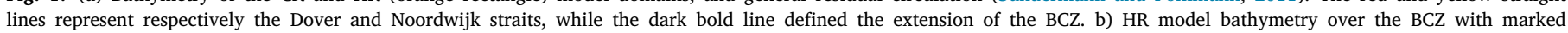

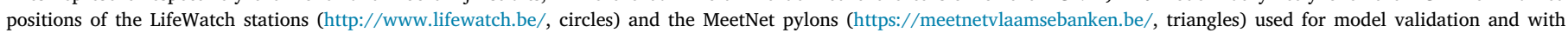
the bathymetry used for the HR model superimposed.

for the HR over the 3-year simulation period). Volume conservation issues in 1-way nesting configuration have been pointed out by Debreu et al. (2012) and Urrego-Blanco et al. (2016), who showed that twoway nesting improves model performance in interface continuity and dynamic integrity compared to one-way nesting. Results of the one-way nesting simulations are not described here.

\section{Description and skill assessment of the simulated hydrodynam-} ics

Here we assess the consistency and quality of simulated results based on the general knowledge of North Sea hydrodynamics and by comparing simulated results with available in-situ and satellite datasets (Table A.1). Model and observations are compared in terms of spatial fields consistency and qualitatively (class 1), time series assessments at specific locations (class 2) and derived quantities (class 3) using various metrics (Table A.2), as defined by Global Ocean Data Assimilation Experiment (GODAE) and CMEMS product quality strategic plan (https://marine.copernicus.eu/wp-content/uploads/2017/03/ CMEMS-PQ-StrategicPlan-v1.6-1.pdf). The benefit of using a higher resolution for the $\mathrm{BCZ}$ is discussed by comparing the $\mathrm{CR}$ and $\mathrm{HR}$ simulations.

\subsection{Tides}

The SBNS and the EC are highly affected by tidal currents, that are responsible for sediment resuspension and vertical mixing. With depths usually shallower than $50 \mathrm{~m}$, the SBNS is a region of intense tidal energy dissipation (Flather, 1976). However, due to the circular character of tides, their resulting impact on general transport is expected to be negligible compared to residual currents, except for regions of tidal asymmetry (Stanev et al., 2014). In agreement with the general knowledge on tidal dynamics in the SBNS and the EC, the cotidal chart of the M2 constituent shows the presence of two amphidromic nodes: in the center of the SBNS and near the coast of the Southern UK in the English Channel (Fig. 2a compare with Prandle, 1980; Hashemi et al., 2015). The distribution of tidal currents over the BCZ results from interactions of the tidal waves around them.

In shallow water, the nonlinearities due to the bottom friction and the advection term generate non-linear tides. The advection term is expected to generate overtides (M4) of twice the frequency of the astronomic M2 tide, while the friction term is responsible for the generation of the odd harmonics (e.g. M6) (Le Provost, 1991). As demonstrated by Stanev et al. (2014), despite being one order of magnitude smaller than the dominant M2, nonlinear tides are more important for sediment transport dynamics in coastal areas due to their strong asymmetry. Table A. 3 compares the simulated and observed tidal amplitudes and phases for M2, S2, M4, M6 at the tide gauges indicated in Fig. 2a. The model performances for M2 and S2 tidal amplitudes and phases are excellent, while for M4 and M6 they degrade for the amplitude (but are still excellent for the phase). The performances of the CR and HR models are generally similar for the major tidal constituents and M4, while the CR model is slightly worse for M6, but without striking differences.

The model simulates different shapes and inclination angles of the tidal ellipses when moving offshore from the Belgian coast (Fig. 2b). Along the coast, tidal ellipses are oriented quasiparallel to the coastline, less eccentric, and the tidal velocities along the major and minor axes are respectively $0.4-0.6 \mathrm{~m} / \mathrm{s}$ and $0.2 \mathrm{~m} / \mathrm{s}$. Offshore, tidal ellipses have an inclination parallel to the northern direction, are flattened, and the tidal velocity along the major axis increases up to $1 \mathrm{~m} / \mathrm{s}$ while that along the minor axis is less than $0.2 \mathrm{~m} / \mathrm{s}$. This rotation of the tidal ellipse when moving offshore from the coast is also found in Davies and Furnes, 1980. For in-situ observations of surface tidal currents we rely on the Meetnet pylons that are located close to the Scheldt estuary. The simulated M2 tidal ellipses show a model disagreement with in-situ observations, as regards the inclination at pylons MP0 and MP4 and for the intensity at MP3 (Fig. 2c). This disagreement can be explained by the complex bathymetry and estuarine dynamics, which would require a higher resolution and an additional level of nesting to be properly resolved. We note however that the model performances in terms of simulating the tidal amplitudes and phases (Table A.3) are comparable to those of coupled river-estuary-coastal models (cf. Table 3 in De Brye et al., 2010).

\subsection{Residual currents and transport}

The residual circulation, defined as the averaged Eulerian circulation over the period of simulation (2006-2008), is significantly smaller (by two orders of magnitude) than the tidal circulation. However, it is responsible for the long-term advection of water masses from the Atlantic, entering the NWES through its south-western boundary (Dover strait) and leaving the NWES through its northern boundary (Noordwijk strait, Fig. 1a). 


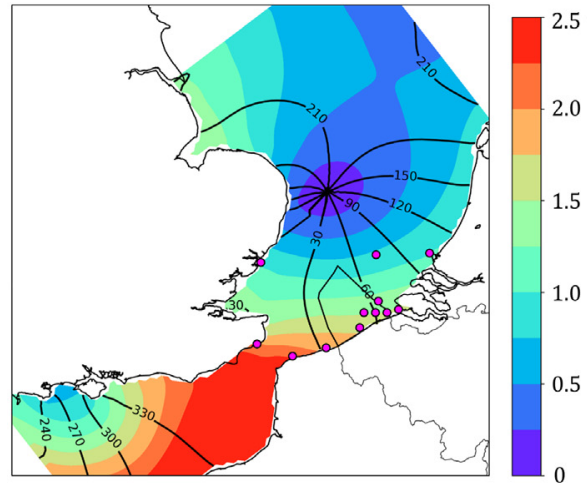

a)

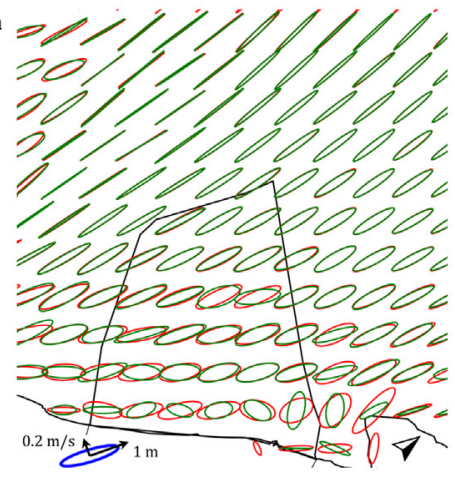

b)

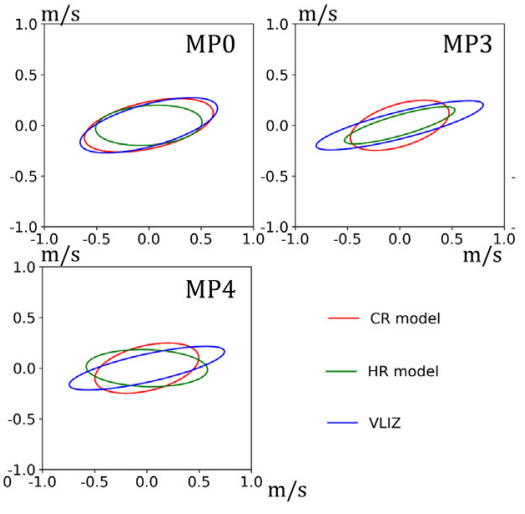

c)

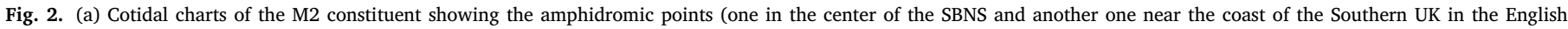

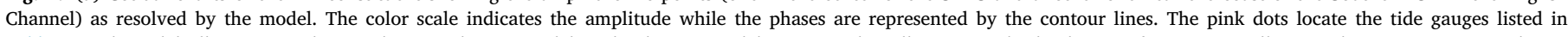

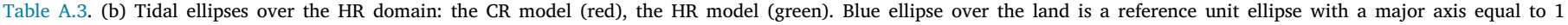
$\mathrm{m} / \mathrm{s}$ and the minor axis equal to $0.2 \mathrm{~m} / \mathrm{s}$. (c) Tidal ellipses for the M2 at the MeetNet pylons simulated by the HR and CR models (see location in Fig. $1 \mathrm{~b}$ ).

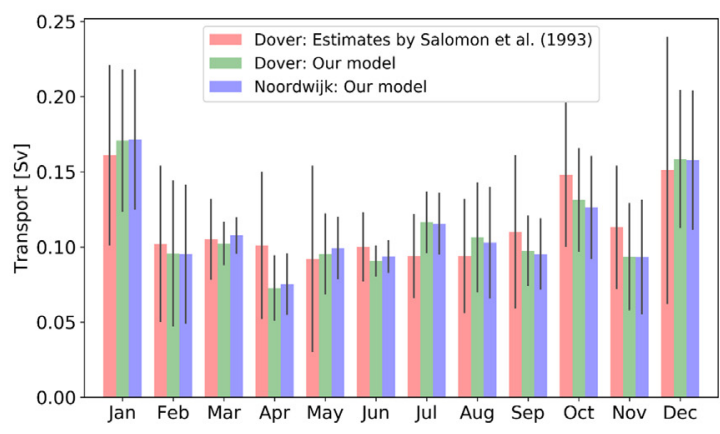

a)

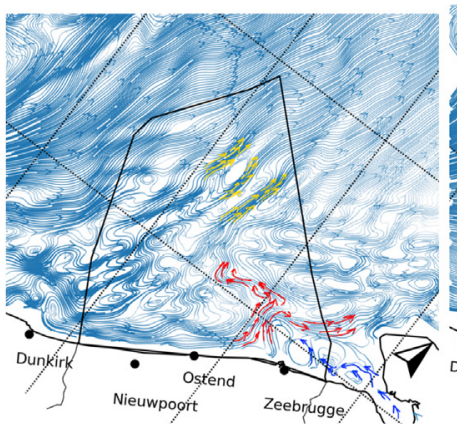

b)

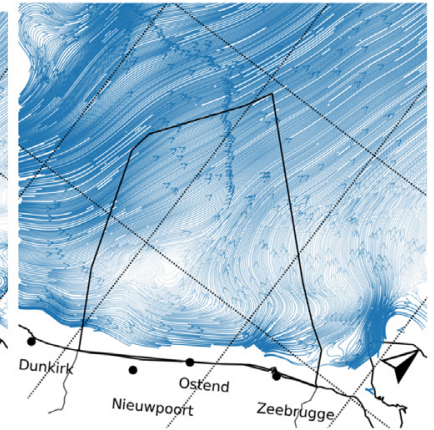

c)

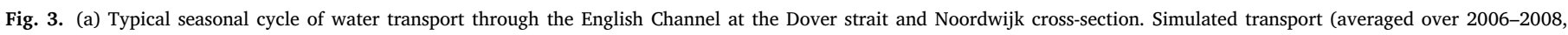

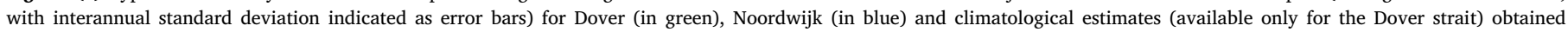

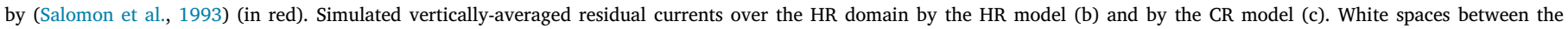
streamlines indicate low velocities areas; and areas, where currents form a spiral, indicate the presence of eddies or gyres.

Fig. 3a shows that the model is able to reproduce the typical seasonal cycle of water transport through Dover strait in agreement with previous studies (Salomon et al., 1993). The model results are, for each month, within the climatological range of variability with an averaged value of $0.111 \mathrm{~Sv}$ (our simulations), against $0.114 \mathrm{~Sv}$ (Salomon et al., 1993), 0.094 Sv (CMEMS models) and 0.07 Sv (NEMO reanalysis, Wakelin et al. 2015). Fig. 3a also displays the simulated transport at Noordwijk, but the lack of observation-based estimates there prevents a model-data comparison. The annual flow is $0.4 \%$ larger across the Noordwijk strait than at the Dover strait, due to an additional riverine input.

Vertically-averaged residual currents simulated by the HR model (Fig. 3b) illustrate that the spatial variability in current fields, their intensity and the presence of mesoscale gyres are enhanced in the HR model compared to the CR model (Fig. 3c) (further investigation in Section 5.2). The interaction of tidal currents with the bathymetry results in formation of permanent gyres, which can be distinguished on the maps of residual currents. Those gyres are expected to be particularly important for the sediment transport, because they act as places of active particle trapping and deposition. For instance, a well-marked $(10 \mathrm{~km})$ gyre, already identified by Fettweis and Van den Eynde (2003), is simulated next to Zeebrugge near the Scheldt estuary. The vast zone with low horizontal velocities in the shallow areas $20-30 \mathrm{~km}$ offshore from Zeebrugge corresponds to an area of high mud deposition with surface currents moving offshore (Fig. A.1b) and bottom currents (Fig. A.1a) moving to the coast as previously identified by Fettweis and Van den Eynde (2003). This bottom countercurrent compensates Scheldt waters moving offshore within the vertically stratified Scheldt-Rhine plume.

The bottom residual currents (derived from simulated velocities at the centers of the deepest grid cell, which is located between several $\mathrm{cm}$ to a couple of meters from the bottom) are significantly smaller than surface currents with typical intensity of $0.02 \mathrm{~m} / \mathrm{s}$, except in the areas of bottom ripples, across the Dover Strait and along the Eastern Noordwijk, where they can reach $0.05 \mathrm{~m} / \mathrm{s}$. The bottom currents are slightly deviated counterclockwise from the surface in the central part of the SBNS, which is caused by difference between the bottom trench orientation and the dominant winds. In the central part of the BCZ, three elongated bottom ripples form zones of current acceleration and deceleration, which cross the wind farms area in the north (Fig. 3b, yellow arrows). Interestingly, the bottom current there diverges from the surface on $90^{\circ}$ clockwise (Fig. A.1). The model simulates the current coming from Scheldt and going westward towards Zeebrugge (Fig. 3b, blue arrows), also identified by Arndt et al. (2011). There, this current is dividing into two branches: one flowing perpendicular to the coast and another one flowing north-east (Fig. 3b, red arrows).

\subsection{Salinity and river plume extension}

In agreement with current knowledge (e.g. Lacroix et al., 2004; Pätsch et al., 2017), salinity distribution over the SBNS can be described by a quite homogeneous water mass coming from the Atlantic and flowing in the central part of the EC and the SBNS with a typical SSS 

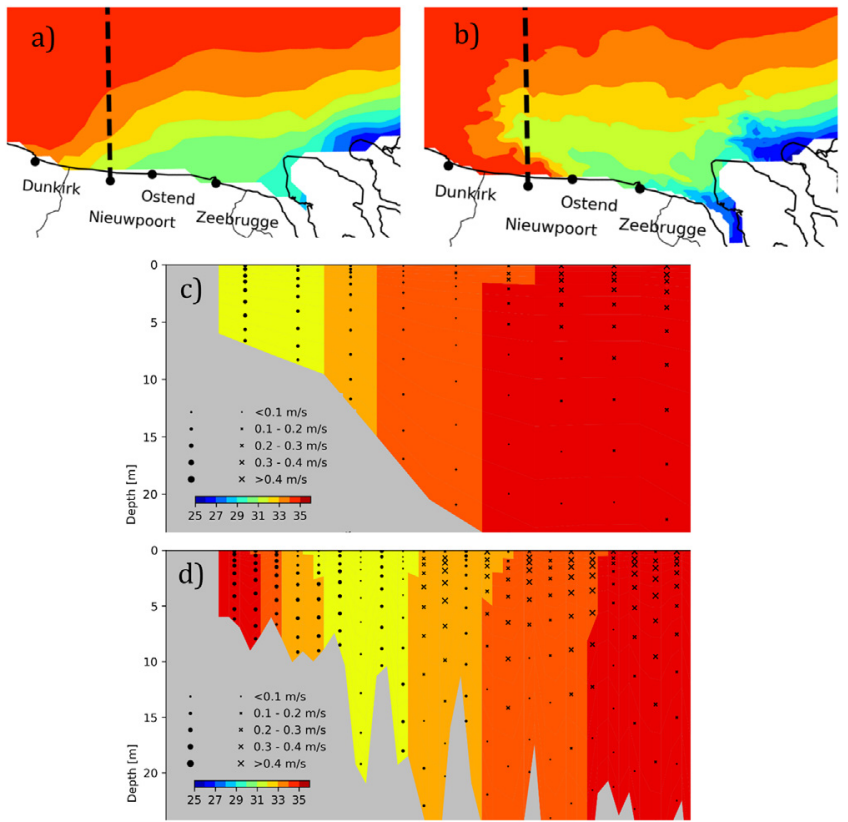

Fig. 4. A salinity plume snapshot (at $12: 00$ Julian day 200) simulated by the CR (a) and the HR (b) models. Salinity vertical transects simulated by the CR (c) and the HR (d) models correspondingly. The position of the vertical section is shown in (a) and (b) by the dashed line. Instantaneous velocity vectors: $(x)-$ water flows from us, (o) water flows towards us; the size of a symbol corresponds to the magnitude of a tidal current.

around 34, and separated by a haline front from English and continental coastal waters influenced by river discharges.

The combined Rhine-Scheldt plume (also evidenced by Holt et al., 2005) first acts as a source of sedimentary material. In addition, the haline stratification inside the plume prevents the transfer of surface wind energy to the lower layer and thus reduces bottom stress and the transfer of bottom resuspended material to the upper layer. Reproducing the variability of the fresh water plume is thus critical for an accurate representation of the BCZ hydrodynamics (Delhez and Carabin, 2001).

The comparison of the simulated and observed SSS (data description in Table A.1) shows that both the HR and CR models have comparable skills in terms of RMS and bias, with an annual RMS of 1.45 and 1.54 and bias of 0.3 and -0.07 for respectively the CR and HR models (Table A.4). Hence none of the two models demonstrates an important systematic error over the year. Over the year, seasonal biases range between -0.54 and 1.08 for the CR model and between -0.84 and 0.97 for the HR model (Table A.5). In terms of RMS, both models show the worst performance in spring (1.81 and 1.93 for $\mathrm{CR}$ and HR models respectively), while the CR shows the best performance in summer (0.87) and the HR in autumn (1.03). The HR model gives better performance (in terms of bias, percentage bias (PB) and RMS) during winter and autumn while in spring and summer the CR model performs better. In order to enhance model performances, finer resolution model implementations also require a finer input of bathymetry, coastline, river discharge and atmospheric conditions, which were not available. The lower performances of the HR model compared to the CR model during spring and summer can be explained considering the higher variability and sharper gradients simulated by the HR model for the freshwater plume (Figs. 4a,b). At the end of spring and during summer, the larger river runoffs and weaker winds intensify the frontal gradient and stimulate baroclinic instabilities. These instabilities are more marked in the HR with stronger deviations on both sides of the frontal zone that challenges the matching with punctual data collected around the frontal interface, hence penalize RMS values. We note however that
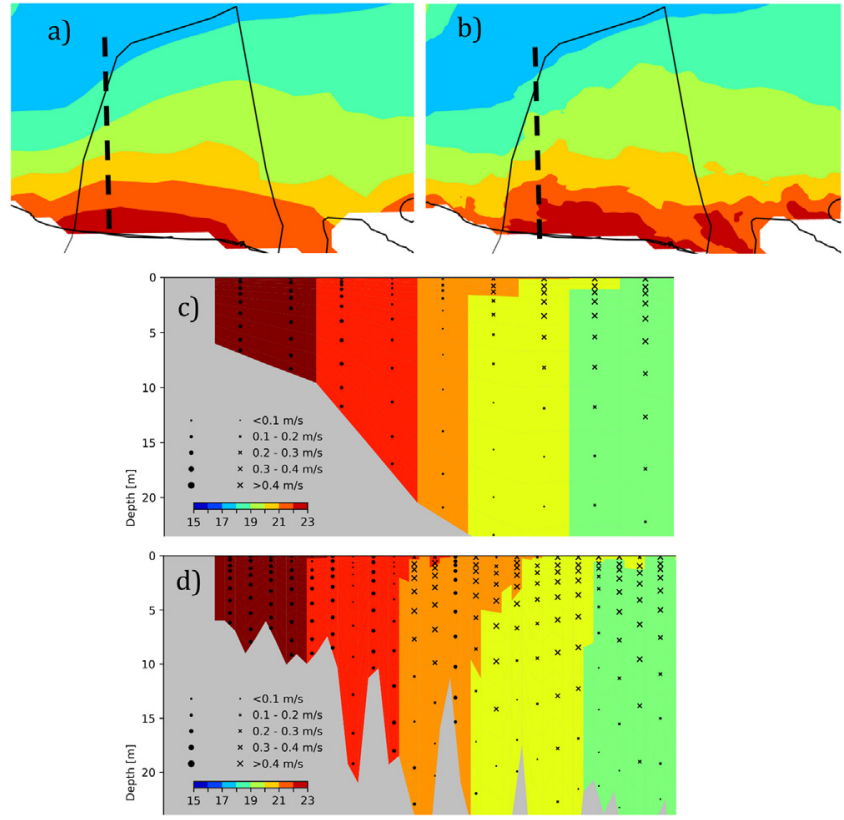

Fig. 5. A temperature snapshot (at 12:00 Julian day 200) simulated by the CR (a) and the HR (b) models. Temperature vertical transects simulated by the CR (c) and the HR (d) models correspondingly. The position of the vertical section is shown in (a) and (b) by the dashed line. Instantaneous velocity vectors: $(x)-$ water flows from us, $(0)-$ water flows towards us; the size of a symbol corresponds to the magnitude of a tidal current.

the model biases during this period are not high $\left(-0.84{ }^{\circ} \mathrm{C}\right)$ indicating the absence of a systematic error.

Comparing the HR and CR salinity patterns clearly confirms that the simulated plume dynamics is sensitive to the spatial resolution. The comparison of the SSS distribution simulated by the CR and HR models (Fig. 4a and b) highlights the ability of the HR to represent non-linearities of the haline frontal interface with a sharp confinement of fresh waters inside the plume and mesoscale excursions of the front, that lead to offshore extension of the plume. In contrast, in the CR model (Fig. 4a) the frontal interface is straight and the plume extends alongshore with reduced offshore extension, leading to slightly worse performance on the most remote stations: ZG02 and 215 (Fig. 1b). In Section 5, the dynamics of the salinity plume is further investigated in connection with meteorological and tidal conditions and we characterize the difference of variability simulated by the HR and CR models. A vertical section across the plume shows that the HR model gives a more detailed description of the salinity vertical gradients and of tidal currents across the plume, including the alongshore countercurrent (Fig. 4b and d compare to Fig. 4c and a), resulting in plume detachment from the coast and its drift offshore (further investigation in Section 5.2).

\subsection{Sea surface temperature}

The SST is validated spatially against satellite-derived data from Copernicus and within the $\mathrm{BCZ}$ against observations collected at fixed stations by the Flanders Marine Institute (description of both products in Table A.1). For comparison with the satellite product, model results are interpolated on the satellite grid and daily-averaged fields are compared using the error metrics defined in Table A.2; while for the in-situ product, point-to-point comparison is performed.

The simulated and observed seasonal cycle of SST is well marked with a minimum of $7{ }^{\circ} \mathrm{C}$ (averaged over the domain) at the end of February-early March and a maximum of $19{ }^{\circ} \mathrm{C}$ reached in mid-July (Fig. A.2b). The interannual variability around these domain-average 

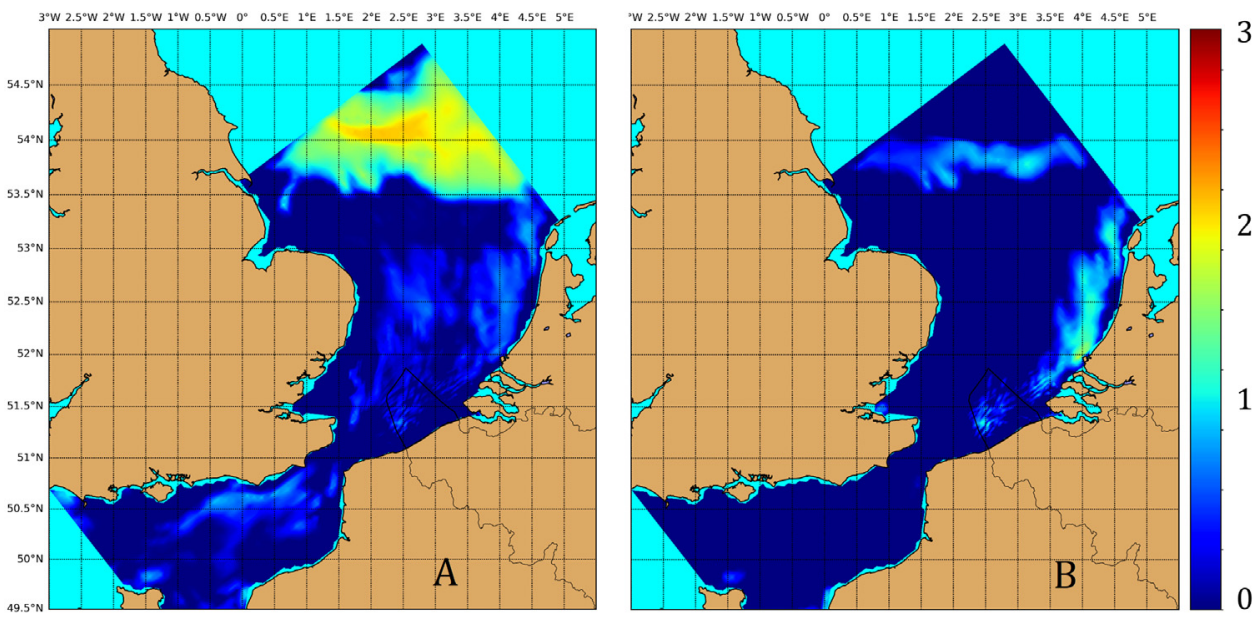

Fig. 6. PEA in summer (Julian day 200) simulated by our models: contribution of (A) temperature and (B) salinity.

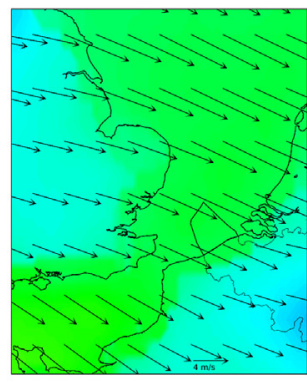

a)

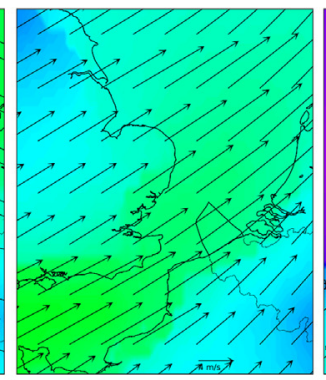

b)

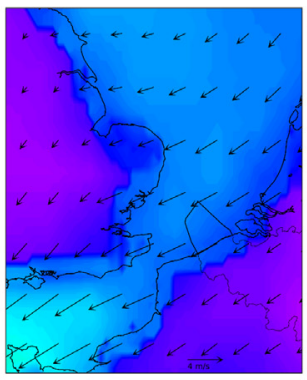

c)

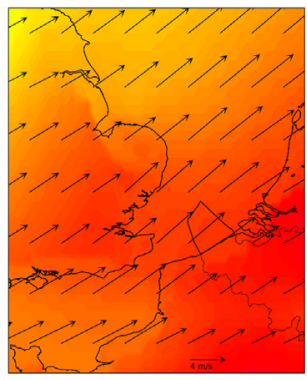

d)

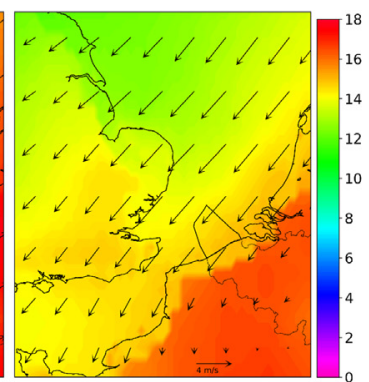

e)

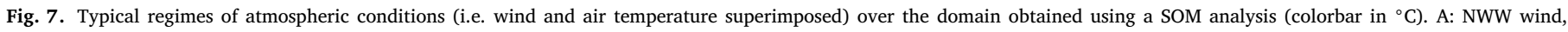
$9{ }^{\circ} \mathrm{C}$ (over the BCZ); B: Strong SW wind, $9{ }^{\circ} \mathrm{C}$; C: NEE wind, $4{ }^{\circ} \mathrm{C}$; D: SW wind, $16{ }^{\circ} \mathrm{C}$; E: NNE wind, $14{ }^{\circ} \mathrm{C}$.

maximum and minimum values is quite limited to respectively $\pm 2{ }^{\circ} \mathrm{C}$ and $\pm 1{ }^{\circ} \mathrm{C}$. In winter (Fig. A.2a), the intrusion of warm Atlantic water masses contrasts with cold river inputs in the coastal area while in summer, the reverse is true and ROFIs waters are warmer. The spatial distribution of bias does not show a marked structure except for a slightly higher bias in the ROFI regions (not shown). Over the season, the bias and RMS vary between $0.01-0.88{ }^{\circ} \mathrm{C}$ (annual: $0.4{ }^{\circ} \mathrm{C}$ ) and 0.48-1.07 ${ }^{\circ} \mathrm{C}$ (annual: $0.77^{\circ} \mathrm{C}$ ) respectively. The annual Nash-Sutcliffe Model Efficiency and percentage bias (respectively NSME and PB, both defined in Table A.2) are respectively of 0.98 and 3.37 which means that the model can be qualified as "excellent" when compared with satellite SST (Allen et al., 2007a). Over the HR domain, the HR and CR models have very similar performances when compared to the satellite SST with annual bias of respectively $0.37{ }^{\circ} \mathrm{C}$ and $0.38{ }^{\circ} \mathrm{C}$ and RMS of $0.72{ }^{\circ} \mathrm{C}$ and $0.69^{\circ} \mathrm{C}$. They are both qualified as excellent based on their NSME ( 0.98 for both models) and PB (3.1\% and $2.49 \%$ for respectively the CR and HR models). The point to point comparison with Lifewatch SST shows that both models have similar performances as concerns the bias and $\mathrm{PB}\left(0.43{ }^{\circ} \mathrm{C}\right.$ and $\left.3.66 \%\right)$ while the $\mathrm{CR}$ has a lower RMS $(0.76$ compared with 0.82 in the HR model) and a standard deviation ratio slightly closer to 1 (see Tables A.4 and A.5 for details). As for the salinity, Fig. 5 shows a snapshot of the temperature field that highlights the presence of a temperature front separating warmer coastal waters from offshore. It is worth to note that the thermal gradient is not aligned with the haline gradient separating the freshwater plume from ocean waters. This creates a complex frontal interface, simulated in more details by the HR model, that exhibits enhanced meandering and undulations. This higher variability may explain the lower performances of the HR model during summer (RMS is 1.06 for the HR compared to 0.85 for the $\mathrm{CR}$ ) when the gradient is more marked and instabilities are favored.

\subsection{Stratification}

The strong energy dissipation due to winter storms and tides makes the SBNS, and, in particular the BCZ, vertically mixed in winter, with the vertical temperature difference not exceeding $0.1^{\circ} \mathrm{C}$ anywhere on the domain, except for very small areas in ROFI regions around the Rhine and Scheldt estuaries. In agreement with past studies (e.g. Delhez, 1996), the EC and particularly Dover strait, are well mixed by bottom friction due to intense tidal currents and storm mixing, while the northern part of the SBNS is less mixed due to larger depths, weaker currents and thermal stratification in summer. In summer, the distribution of the potential energy anomaly (PEA, Table A.2) shows that most of the regions are still well-mixed (vertical temperature gradient is less than $1^{\circ} \mathrm{C}$ ), except in the northern part of the SBNS, where a strong thermocline establishes (vertical gradient reaches $3^{\circ} \mathrm{C}$ ) (Fig. 6a), and in the plumes of the Rhine and Scheldt, where a local halocline prohibits warming of deep waters. The results are in line with previous studies (Fig. 4 from Holt et al., 2005).

The haline stratification (Fig. 6b) in ROFI regions, also evidenced in Holt et al. (2005), is expected to affect the transfer of river substances and sediments from the estuarine plume to offshore (e.g. Fettweis and Van den Eynde, 2003) and, along the vertical, to inhibit the vertical exchange through resuspension and sedimentation. Despite the presence of a plume at its mouth, the Scheldt is generally well-mixed inside its channel, due to a high ratio between tidal inflow and the river's proper discharge.

\section{Variability of the BCZ hydrodynamics}

Here we describe the variability of selected traits of the BCZ hydrodynamics (plume extension and currents) by illustrating their response 

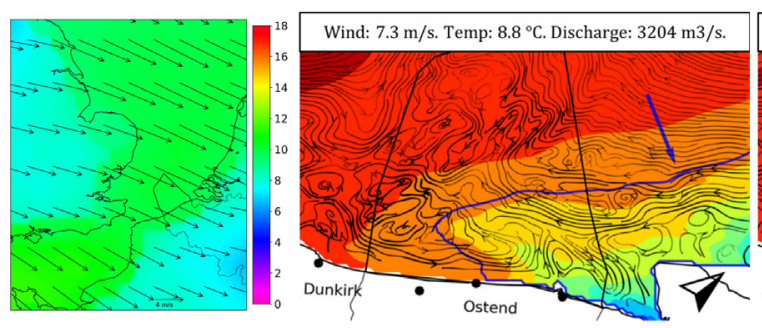

A1
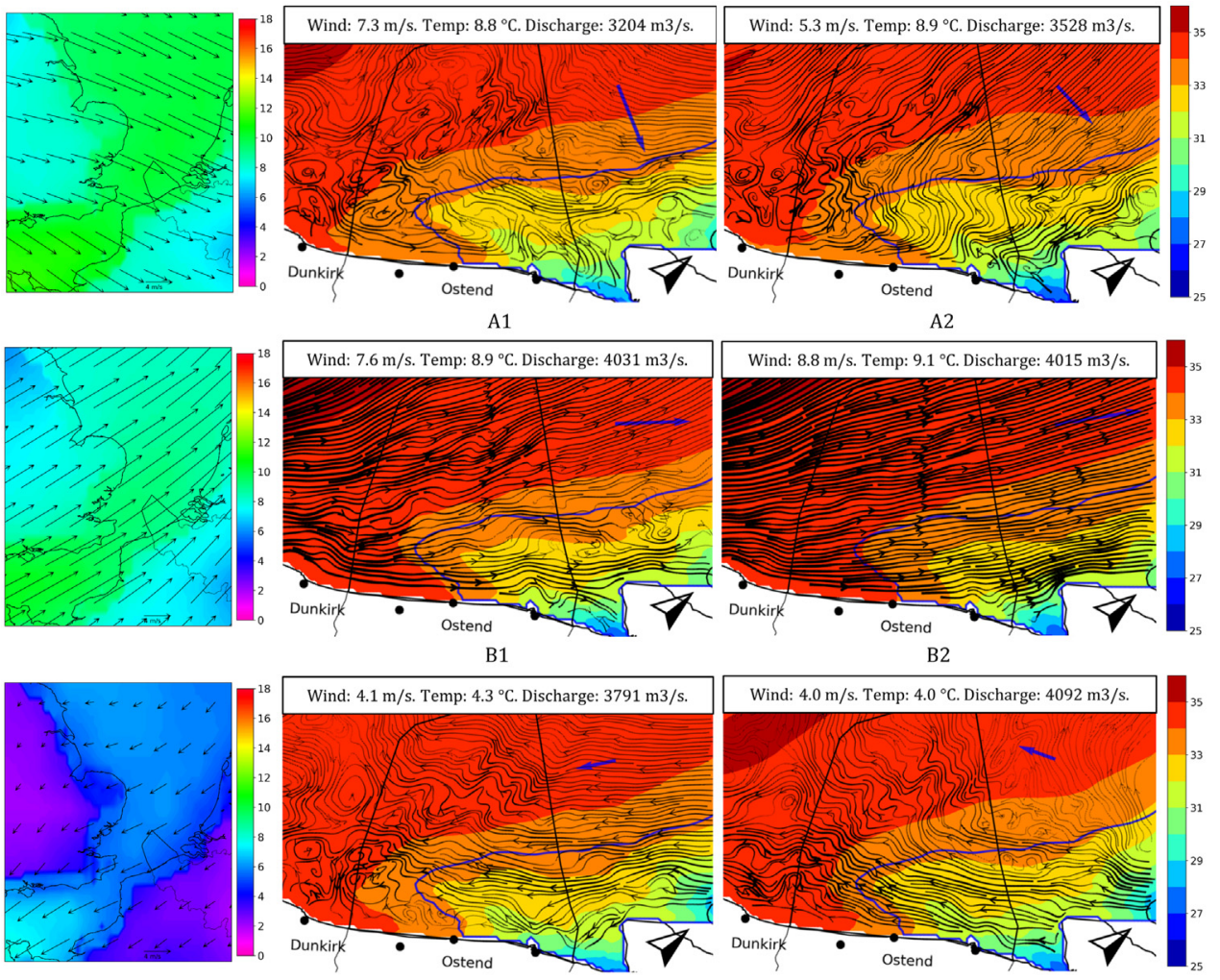

B2

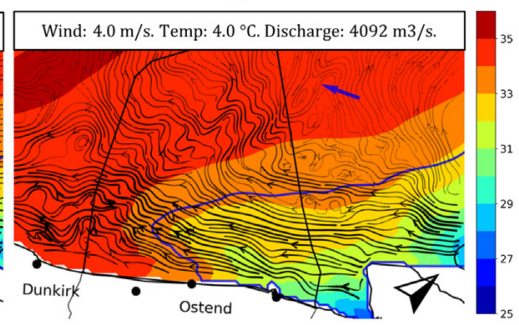

C2
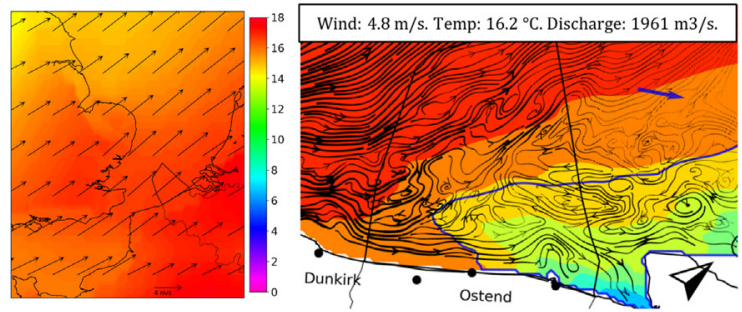

D1
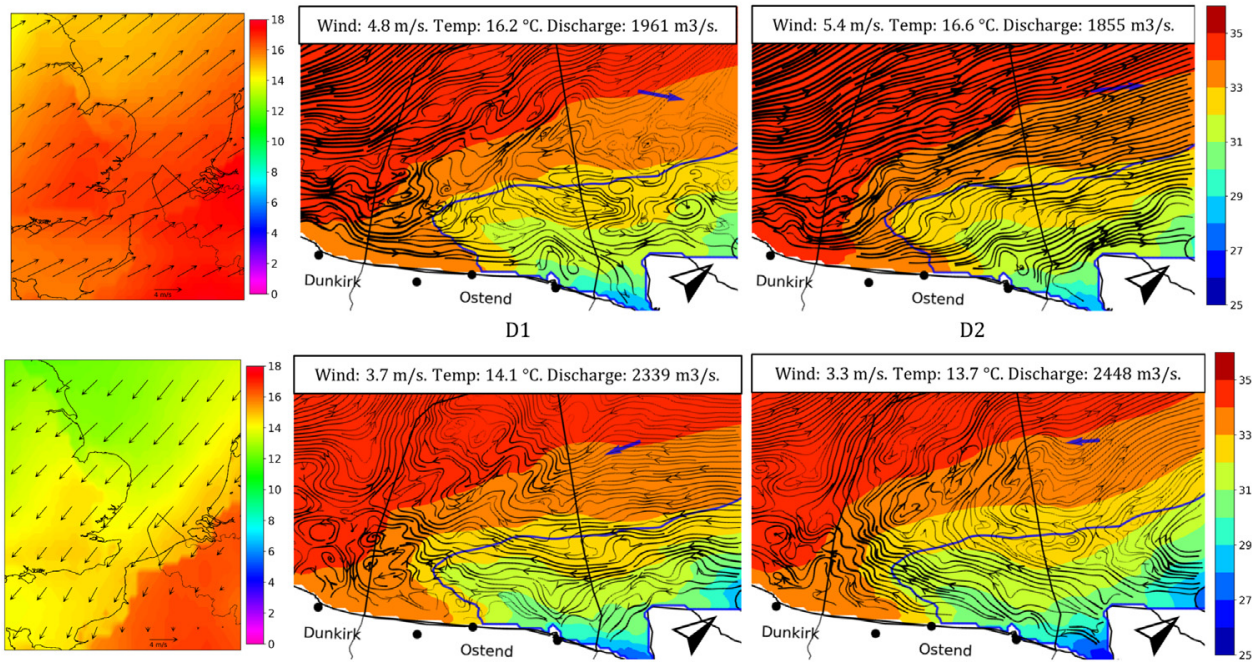

E1

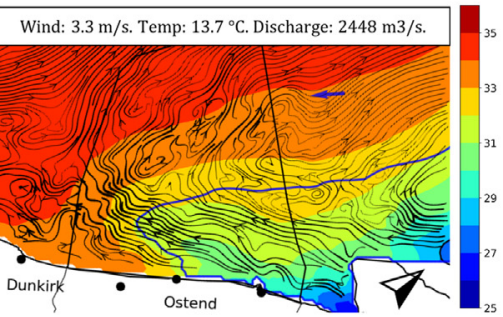

E2

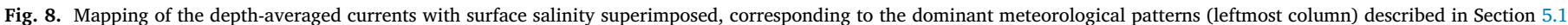

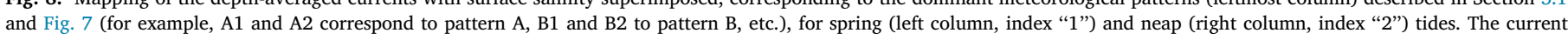

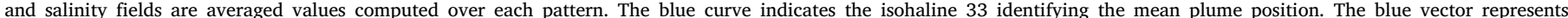

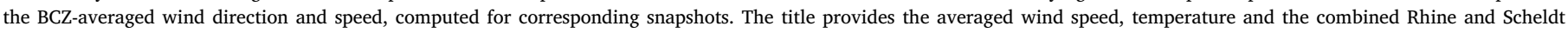
water discharge.

to the dominant external forcings: atmospheric conditions (winds and air temperature) and tides (spring and neap regimes). We also demonstrate the limitation of the CR model in resolving important aspects of this variability. We do not test the impact of the variability of the far field circulation on the SBNS and BCZ hydrodynamics as previous studies (Delhez, 1996) found, that the daily and seasonal variability of the hydrodynamic conditions in the SBNS and, in particular, the regime of residual gyres in the BCZ, are mainly driven by the local weather and tidal conditions rather than by the large-scale circulation. Here, the impact of the far field circulation is imposed through boundary conditions (daily-averaged values of currents, temperature and salinity, plus tidal conditions). A sensitivity analysis performed by putting to zero the barotropic components of the daily currents at the open boundaries shows, that the obtained hydrodynamic patterns in terms of plume extension and daily-average circulation are not substantially changed (not shown).

\subsection{Identification of typical regimes of atmospheric conditions}

Four main forcing factors drive the general circulation over the NWEC: the Atlantic water flow at its lateral boundary, the non-linear interactions of residual currents with tidal currents, the atmospheric 


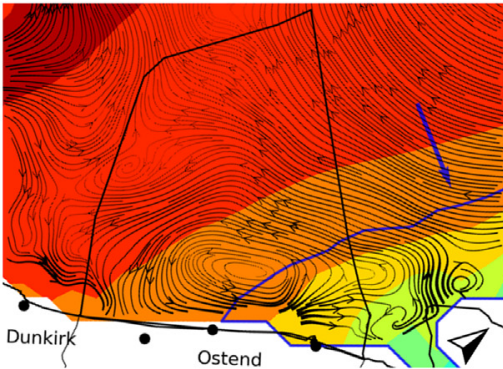

a)

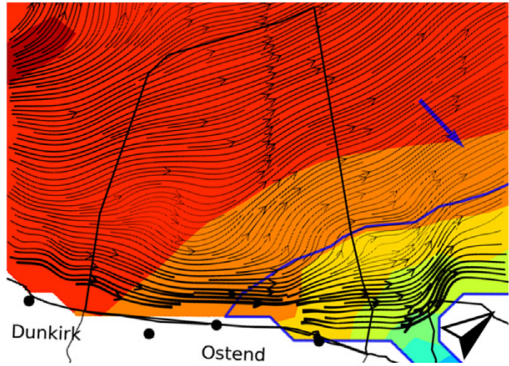

c)

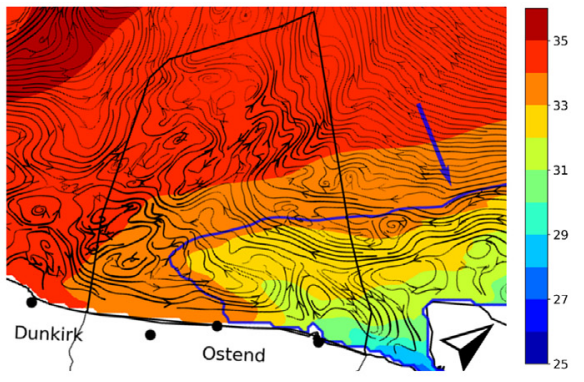

b)

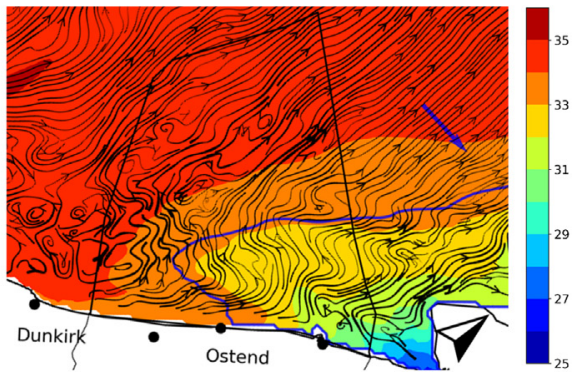

d)

Fig. 9. Currents and SSS associated to Pattern A for spring (a,b) and neap (c,d) tides simulated by the CR (a,c) and HR (b, d) models.

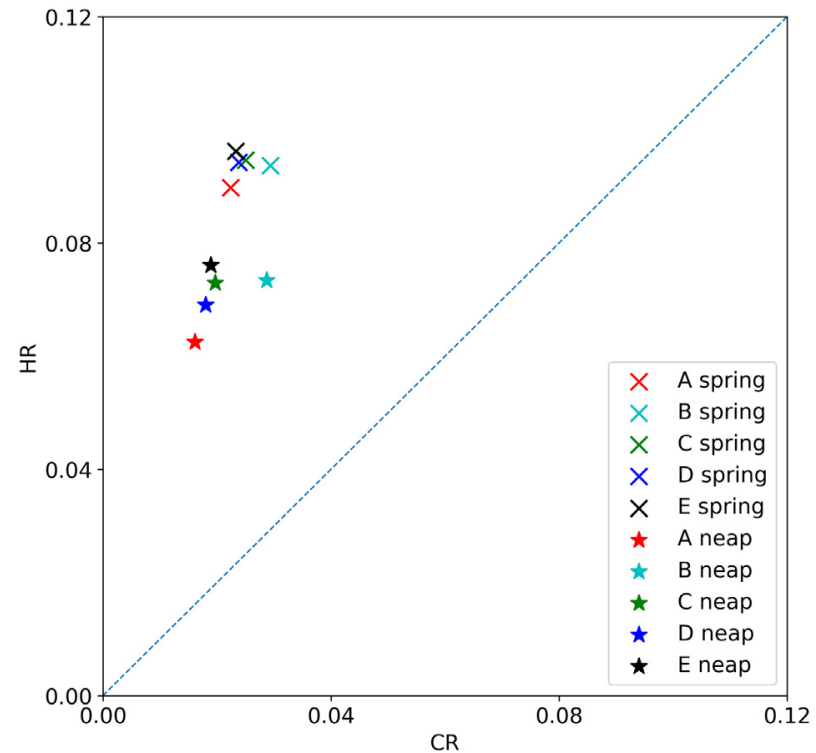

Fig. 10. Normalized vertical relative vorticity averaged over the HR domain for the different patterns identified in Section 5.1 and tidal phases, where the $x$-axis - the CR model, the $y$-axis - the HR model.

conditions, and the density differences between the different water masses on the shelf, which in our case is limited to ROFIs. In addition, bottom topography plays a crucial role by trapping currents and generating non-linearities of the mesoscale flow (Delhez, 1996). Considering the role played by atmospheric conditions, typical patterns of wind fields and air temperature are identified using a Self-Organizing Map analysis (SOM, by Kohonen, 1982), to structure the description of hydrodynamic variability (e.g. Richardson et al., 2003; Allen et al., 2007b; Capet et al., 2012). The SOM is a type of artificial neural network, which uses unsupervised learning to classify a large set of events. According to the elbow method (Ketchen and Shook, 1996), the range of atmospheric conditions over the SBNS can be described using five classes of typical weather conditions. The average atmospheric conditions for each class (referred to as "atmospheric pattern" in the
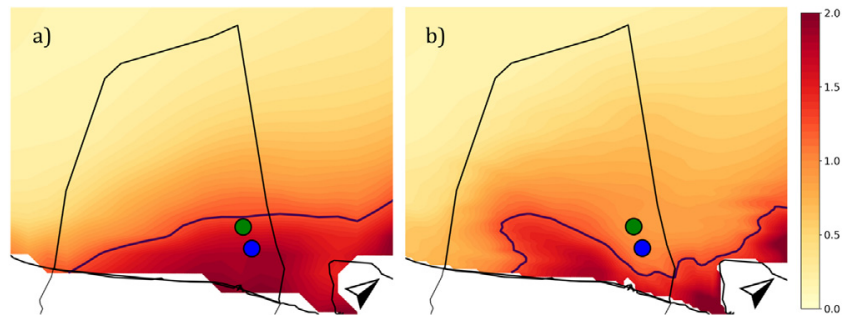

Fig. 11. Temporal standard deviation of SSS for the CR model (a) and the HR model (b). Positions of stations significantly better resolved by the HR are marked by the green (780) and blue (710) dots. The black contour - isoline of 1.25 StD.

following) are depicted in Fig. 7 and used to interpret the variability of hydrodynamic conditions in combination with tidal regimes (i.e. neap or spring).

Table A.6 describes the seasonal occurrence of each pattern. Pattern A depicts strong NWW winds and is equally represented throughout winter, spring and autumn. Pattern B depicts strong SW winds. It is dominant in winter, but also occurs in early spring and late autumn. Pattern $\mathrm{C}$ is typical for winter and early spring, representing cold conditions and a NE wind. Pattern D is predominant in summer and early autumn and depicts warm conditions and intermediate SW winds. Finally, pattern E also depicts NE winds but with warm temperatures typical of summer, early autumn and spring.

\subsection{Response of the BCZ hydrodynamics to different forcing regimes}

The impact of atmospheric regimes on the SBNS hydrodynamics is investigated by comparing the simulated hydrodynamics associated to each pattern, differentiating in addition between neap and spring tidal conditions. Technically this is done as follows: each particular set of atmospheric conditions ( $3 \mathrm{~h}$ temporal resolution) of the three year simulation is mapped to the closest of those five patterns and also mapped towards spring and neap tides or in-between. Each day is then associated with the pattern most represented within the day. Here, the tidal regime (spring, neap, or neither) is identified for each day based on the highest water level during that day (within the BCZ). Days with 
Table A.1

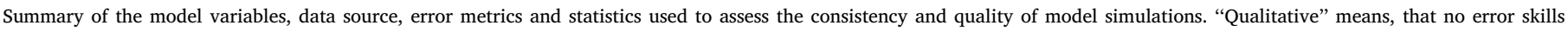
are quantified, but rather a visual comparison of model and data is proposed.

\begin{tabular}{|c|c|c|}
\hline Model Variable & Data & Class of error metrics \& statistics \\
\hline Temperature & $\begin{array}{l}\text { Reprocessed SST }- \text { satellite data from CMEMS for the } \\
\text { Atlantic-NWES, horizontal resolution } 0.04167^{\circ} \\
\text { (SST_NWS_SST_L4_REP_OBSERVATIONS_010_023). }\end{array}$ & Class 1: Bias \& RMS (spatially and/or temporally averaged) \\
\hline $\operatorname{SST}\left[{ }^{\circ} \mathrm{C}\right]$ & $\begin{array}{l}\text { LifeWatch stations: fixed-platforms sampled irregularly (see } \\
\text { Fig. } 2 \text { b for the position). }\end{array}$ & Class 2: Bias, RMS \\
\hline Salinity & $\begin{array}{l}\text { Description of the combined Scheldt and Rhine river plume } \\
\text { (De Brye et al., 2010; Arndt et al., 2011) }\end{array}$ & Class 1: Qualitative: maps, vertical transects \\
\hline SSS & $\begin{array}{l}\text { LifeWatch stations: fixed-platforms sampled irregularly (see } \\
\text { Fig. 2b for the position). }\end{array}$ & Class 2: Bias, RMS \\
\hline $\begin{array}{l}\text { Stratification as a potential } \\
\text { energy anomaly }\left(\mathrm{J} \mathrm{m}^{-3}\right)\end{array}$ & $\begin{array}{l}\text { Map of the potential energy anomaly from literature (Holt } \\
\text { et al., 2005) }\end{array}$ & Class1: Qualitative: maps \\
\hline Residual currents (m/s) & $\begin{array}{l}\text { Maps of residual currents from the literature (Delhez, 1996; } \\
\text { Fettweis and Van den Eynde, 2003; Arndt et al., 2011) }\end{array}$ & Class 1: Qualitative: maps \\
\hline Tidal currents (m/s) & $\begin{array}{l}\text { Knowledge from the literature; In-situ observations at } \\
\text { MeetNet pylons }\end{array}$ & $\begin{array}{l}\text { Class 1: Qualitative: maps of tidal ellipses for M2; Class 2: } \\
\text { Qualitative: tidal ellipses for several constituents }\end{array}$ \\
\hline $\begin{array}{l}\text { Tidal amplitudes }(\mathrm{m}) \text { and phases } \\
\left({ }^{\circ}\right)\end{array}$ & $\begin{array}{l}\text { Knowledge from the literature; Observations at VLIZ pylons; } \\
\text { Tidal gauges observations from Permanent Service for Mean } \\
\text { Sea Level (PSMSL) }\end{array}$ & $\begin{array}{l}\text { Class 1: Qualitative: maps of amplitudes and phases; Class 2: } \\
\text { Bias of amplitudes and phases }\end{array}$ \\
\hline $\begin{array}{l}\text { Transport through Dover and } \\
\text { Noordwijk straits (Sv) }\end{array}$ & $\begin{array}{l}\text { Climatological discharges from Salomon et al. (1993) for } \\
\text { Dover; Modeled discharges for Dover and Noordwijk } \\
\text { (Wakelin et al., 2015) }\end{array}$ & Class 3: Climatological seasonal cycle \\
\hline
\end{tabular}

Table A.2

All used metrics.

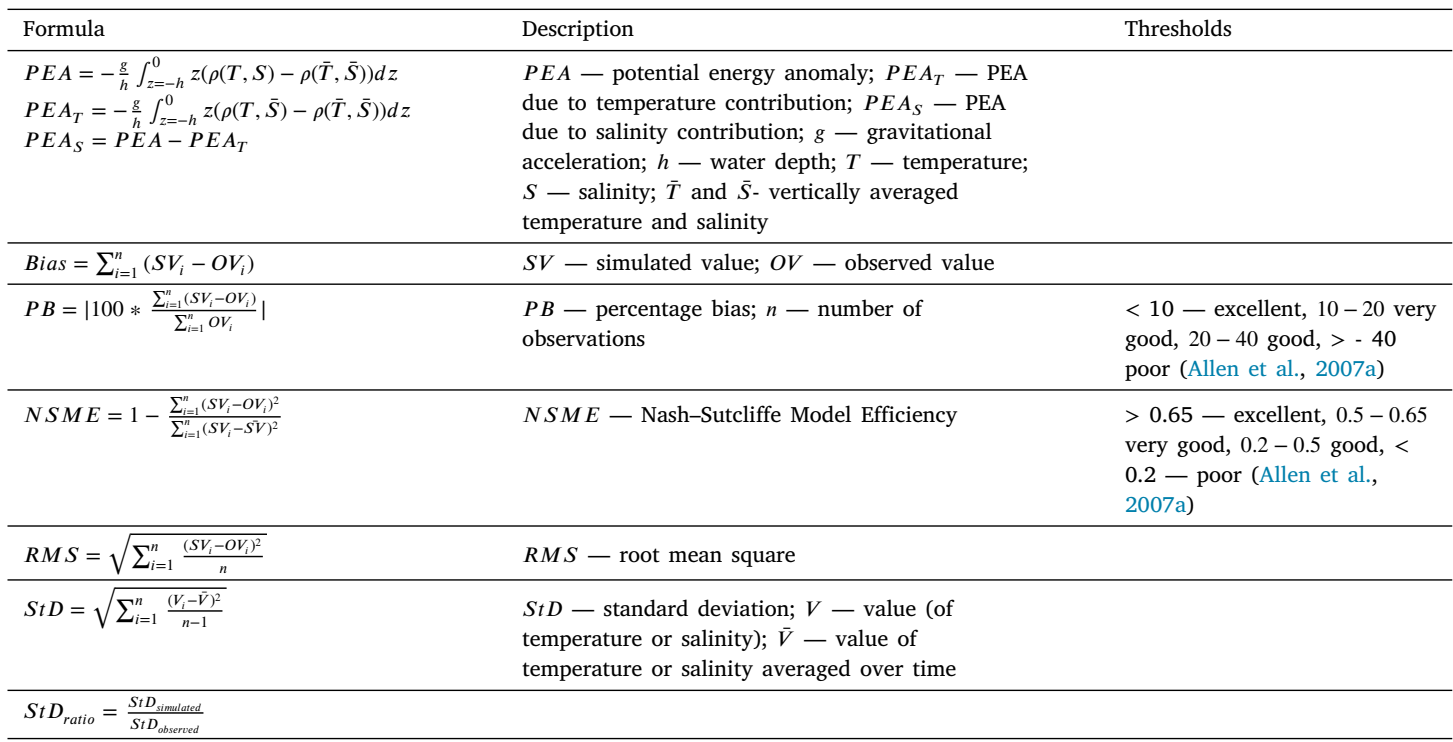

the highest water level higher than $0.9 \mathrm{~m}$ are associated with spring tides, while days with highest water level below $0.6 \mathrm{~m}$ are associated with neap tides. These limits were chosen in order to sustain a relative balance between the number of both spring and neap tides and to provide enough data for the SOM classification. Note that we discuss only the system response to spring and neap tides as the most extreme conditions. The hydrodynamic response associated to each pattern is illustrated as the average of the simulated SSS and currents during those days. To ensure the consistency of this approach, in particular regarding the consistent sampling of tidal phases (which may impact on the depicted currents) a bootstrapping test was performed. The averages for each pattern are replicated three times, while removing $20 \%$ of randomly selected time frames. This procedure confirmed that 1 ) the replicates were qualitatively identical and 2) the difference between patterns remained qualitatively unchanged (not shown). We are thus confident that the currents and salinity fields associated to each pattern are a good representation of the averaged circulation and the river plume.
During the cold period (from late autumn to early spring), patterns A, B and C prevail. When NWW winds dominate (pattern A), the plume extension (delimited by the isohaline 33 ) is slightly smaller than the annual average during both spring and neap tides (Fig. 8A1 and A2). Differently from the river plume, the distribution of currents shows large differences between the neap and spring tidal regime. During neap tides, currents are generally more intense and flow northward, outward of the BCZ, with convergence zones in the Scheldt area near the coast; while during spring tides, they reverse, are weaker and flow towards the BCZ from the Dutch coast, with the Scheldt convergence zones having a wider offshore extension. When strong SW winds dominate the cold period (pattern B), the plume extension is the most reduced and this is the only case, where the plume does not reach Ostend. Currents are dominated by a strong northeastern flow, suppressing all persistent mesoscale structures in the BCZ (Fig. 8B1 and B2). In winter and early spring, when the lowest air temperatures and weak NEE winds prevail (pattern C), the currents are more intense nearshore and generally flow south-westward along the Belgian coast 
Table A.3

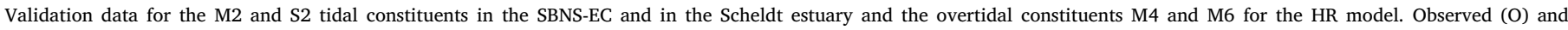

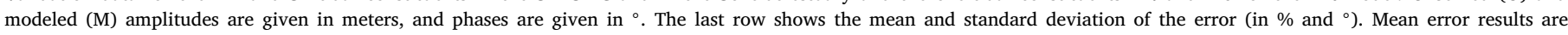
also shown without station Calais (last line of the table) due to its strong influence on the average errors.

\begin{tabular}{|c|c|c|c|c|c|c|c|c|c|c|c|c|c|c|c|c|c|c|c|}
\hline \multicolumn{4}{|c|}{ HR model } & \multicolumn{8}{|c|}{ Principal constituents } & \multicolumn{8}{|c|}{ Overtidal constituents } \\
\hline & & & & \multicolumn{4}{|c|}{ M2 } & \multicolumn{4}{|l|}{ S2 } & \multicolumn{4}{|c|}{ M4 } & \multicolumn{4}{|c|}{ M6 } \\
\hline & & & & \multicolumn{2}{|c|}{ Amplitude [m] } & \multicolumn{2}{|c|}{ Phase $\left[{ }^{\circ}\right]$} & \multicolumn{2}{|c|}{ Amplitude $[\mathrm{m}]$} & \multicolumn{2}{|c|}{ Phase $\left[{ }^{\circ}\right]$} & \multicolumn{2}{|c|}{ Amplitude [m] } & \multicolumn{2}{|c|}{ Phase $\left[{ }^{\circ}\right]$} & \multicolumn{2}{|c|}{ Amplitude [m] } & \multicolumn{2}{|c|}{ Phase $\left[{ }^{\circ}\right]$} \\
\hline$N$ & Station & lat $(N)$ & lon $(E)$ & $O$ & $M$ & $O$ & $M$ & $O$ & $M$ & $O$ & $M$ & $O$ & $M$ & $O$ & $M$ & $O$ & $M$ & $O$ & $M$ \\
\hline 1 & MP0 & 51.394 & 3.046 & 1.62 & 1.5 & 10 & 24 & 0.47 & 0.41 & 63 & 82 & 0.1 & 0.15 & 5 & 333 & 0.08 & 0.06 & 315 & 301 \\
\hline 2 & MP3 & 51.39 & 3.199 & 1.59 & 1.5 & 14 & 30 & 0.46 & 0.41 & 68 & 88 & 0.1 & 0.16 & 22 & 347 & 0.09 & 0.06 & 328 & 331 \\
\hline 3 & MP4 & 51.418 & 3.299 & 1.55 & 1.48 & 19 & 35 & 0.45 & 0.4 & 73 & 93 & 0.11 & 0.17 & 33 & 357 & 0.09 & 0.05 & 341 & 3 \\
\hline 1 & Harwich $^{*}$ & 51.95 & 1.29 & 1.29 & 0.95 & 139 & 139 & 0.37 & 0.27 & 216 & 224 & 0.08 & 0.09 & 312 & 300 & 0.07 & 0.07 & 277 & 271 \\
\hline 2 & Dover $^{*}$ & 51.11 & 1.32 & 2.19 & 2.04 & 146 & 134 & 0.71 & 0.59 & 224 & 216 & 0.25 & 0.24 & 204 & 199 & 0.06 & 0.11 & 101 & 92 \\
\hline 3 & Hoek $^{*}$ & 51.977 & 4.119 & 0.77 & 1.02 & 231 & 231 & 0.19 & 0.26 & 315 & 314 & 0.18 & 0.19 & 88 & 86 & 0.04 & 0.09 & 46 & 76 \\
\hline 4 & Calais* & 50.969 & 1.868 & 2.46 & 2.22 & 156 & 145 & 0.77 & 0.64 & 225 & 226 & 0.27 & 0.22 & 224 & 219 & 0.02 & 0.11 & 59 & 120 \\
\hline 5 & Vlakte & 51.503 & 3.242 & 1.46 & 1.38 & 191 & 192 & 0.42 & 0.38 & 269 & 275 & 0.12 & 0.16 & 16 & 12 & 0.08 & 0.07 & 331 & 346 \\
\hline 6 & Vlissingen & 51.443 & 3.597 & 1.7 & 1.6 & 204 & 204 & 0.48 & 0.43 & 285 & 291 & 0.13 & 0.24 & 43 & 31 & 0.08 & 0.12 & 15 & 87 \\
\hline 7 & Dunkerque & 51.048 & 2.366 & 2.13 & 1.95 & 164 & 159 & 0.62 & 0.55 & 245 & 241 & 0.07 & 0.18 & 266 & 266 & 0.08 & 0.11 & 197 & 181 \\
\hline 8 & Europlatform & 51.998 & 3.275 & 0.71 & 0.8 & 199 & 209 & 0.18 & 0.21 & 281 & 290 & 0.1 & 0.11 & 56 & 56 & 0.04 & 0.05 & 356 & 15 \\
\hline 9 & Ostend & 51.233 & 2.29 & 1.78 & 1.66 & 179 & 176 & 0.54 & 0.46 & 257 & 260 & 0.1 & 0.16 & 316 & 319 & 0.06 & 0.07 & 293 & 264 \\
\hline \multicolumn{2}{|c|}{$\begin{array}{l}\text { Mean error } \\
\text { and std }\end{array}$} & & & \multicolumn{2}{|c|}{$\begin{array}{l}-3.5 \pm \\
14.1 \%\end{array}$} & \multicolumn{2}{|c|}{$\begin{array}{l}2.2 \\
9.8\end{array}$} & \multicolumn{2}{|c|}{$\begin{array}{l}-7.3 \pm \\
17.2 \%\end{array}$} & \multicolumn{2}{|c|}{$\begin{array}{l}6.6 \\
9.3\end{array}$} & \multicolumn{2}{|c|}{$\begin{array}{l}42.1 \pm \\
47.7 \%\end{array}$} & \multicolumn{2}{|l|}{$\begin{array}{l}5.5 \\
18\end{array}$} & \multicolumn{2}{|c|}{$\begin{array}{l}56 \quad \pm \\
133.5 \%\end{array}$} & \multicolumn{2}{|c|}{$\begin{array}{l}12.3 \pm \\
30.8\end{array}$} \\
\hline \multicolumn{2}{|c|}{$\begin{array}{l}\text { Mean error } \\
\text { and std, } \\
\text { without } \\
\text { "Calais" }\end{array}$} & & & \multicolumn{2}{|c|}{$\begin{array}{l}-2.9 \pm \\
14.7 \%\end{array}$} & \multicolumn{2}{|c|}{$\begin{array}{l}3.4 \\
9.3\end{array}$} & \multicolumn{2}{|c|}{$\begin{array}{l}-6.5 \pm \\
17.7 \%\end{array}$} & \multicolumn{2}{|c|}{$\begin{array}{l}7.1 \\
9.6\end{array}$} & \multicolumn{2}{|c|}{$\begin{array}{l}47.6 \pm \\
45.8 \%\end{array}$} & $\begin{array}{l}-12 \\
\pm 1\end{array}$ & & & & $\begin{array}{l}7.9 \\
28.0\end{array}$ & \pm \\
\hline
\end{tabular}

Table A.4

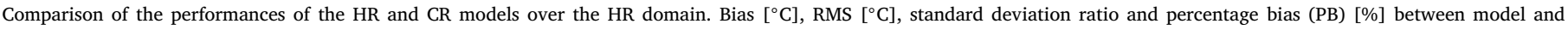

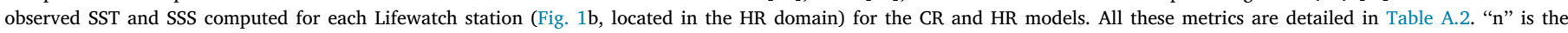
number of measurements.

\begin{tabular}{|c|c|c|c|c|c|c|c|c|c|c|c|c|}
\hline Grid & & & All stations & $\begin{array}{l}120 \\
n=33\end{array}$ & $\begin{array}{l}130 \\
\mathrm{n}=38\end{array}$ & $\begin{array}{l}215 \\
n=23\end{array}$ & $\begin{array}{l}230 \\
n=24\end{array}$ & $\begin{array}{l}330 \\
n=29\end{array}$ & $\begin{array}{l}700 \\
n=23\end{array}$ & $\begin{array}{l}710 \\
n=20\end{array}$ & $\begin{array}{l}780 \\
n=19\end{array}$ & $\begin{array}{l}\text { ZG02 } \\
\mathrm{n}=19\end{array}$ \\
\hline \multirow{6}{*}{ SST } & \multirow{4}{*}{ CR } & Bias & 0.43 & 0.4 & 0.1 & 0.3 & 0.6 & 0.6 & 0.4 & 0.7 & 0.6 & 0.2 \\
\hline & & PB & 3.66 & 4.5 & 1 & 2.8 & 5.4 & 4.4 & 3.2 & 5.5 & 5.2 & 1.9 \\
\hline & & RMS & 0.76 & 0.6 & 0.8 & 0.5 & 1.0 & 0.7 & 0.5 & 1.0 & 1.0 & 0.5 \\
\hline & & Std Ratio & 1.04 & 1.01 & 1.11 & 0.99 & 1.06 & 1.05 & 1.02 & 1.03 & 1.05 & 0.98 \\
\hline & \multirow{4}{*}{ HR } & Bias & 0.43 & 0.4 & 0.1 & 0.3 & 0.6 & 0.8 & 0.4 & 0.5 & 0.4 & 0.3 \\
\hline & & $\mathrm{PB}$ & 3.66 & 4.7 & 0.9 & 2.6 & 5 & 6 & 3.4 & 4.3 & 3.4 & 2.8 \\
\hline & & RMS & 0.82 & 0.7 & 0.9 & 0.7 & 1.0 & 1.1 & 0.7 & 0.7 & 0.7 & 0.6 \\
\hline \multirow{9}{*}{ SSS } & & Std Ratio & 1.07 & 1.04 & 1.13 & 1.07 & 1.08 & 1.11 & 1.06 & 1.02 & 1.01 & 1.02 \\
\hline & \multirow{4}{*}{ CR } & Bias & 0.3 & 1.2 & 0.6 & 0.7 & 0 & 0 & 0.2 & -0.5 & -0.5 & 0.4 \\
\hline & & PB & 0.92 & 3.7 & 1.7 & 2.2 & 0 & 0 & 0.6 & 1.6 & 1.7 & 1.3 \\
\hline & & RMS & 1.45 & 1.8 & 1.8 & 1.1 & 1.2 & 0.6 & 1.9 & 1.6 & 1.3 & 0.7 \\
\hline & & Std Ratio & 1.22 & 0.87 & 0.89 & 0.77 & 1.66 & 0.96 & 2.88 & 2.25 & 1.97 & 0.66 \\
\hline & \multirow{4}{*}{ HR } & Bias & -0.07 & 1.6 & 0.5 & -0.2 & -0.4 & -1.1 & -0.9 & -0.3 & -0.5 & -0.1 \\
\hline & & PB & 0.23 & 4.9 & 1.5 & 0.6 & 1.4 & 3.4 & 3 & 1 & 1.7 & 0.2 \\
\hline & & RMS & 1.54 & 2.2 & 1.9 & 0.7 & 1.5 & 1.5 & 1.8 & 0.8 & 0.9 & 0.7 \\
\hline & & Std Ratio & 1.13 & 0.68 & 0.87 & 1.16 & 1.47 & 1.07 & 2.35 & 1.09 & 0.95 & 1.07 \\
\hline
\end{tabular}

(Fig. 8C1 and C2), contrary to the previous cases. Offshore, the NEE winds strongly reduce the general northward current and lead to the creation of multiple gyres. The lack of mesoscale structures within the plume is a possible consequence of higher water discharge of the Rhine and Scheldt in these seasons and the absence of stratification. During spring tides, we note however undulations of the coastal current that lead to the generation of a small gyre western of Ostend. The plume extension is slightly reduced.

During the warm period (from late spring to early autumn), patterns $\mathrm{D}$ and $\mathrm{E}$ prevail. With pattern D (dominant in summer), SW winds dominate and the plume extension is similar or even slightly higher than the average. Offshore, the general current direction is north-east for both spring and neap tides (Fig. 8D1 and D2). However, due to the presence of thermal stratification in summer, currents within the plume form a variety of clockwise and counterclockwise gyres and zones of low currents during spring tides. During neap tides, most of the gyres are suppressed, while still leaving the convergence zone along the ripples oriented north-east. When pattern E prevails, relatively weak NNE winds dominate, the plume extension is significantly larger than the average, extending southwestward from Nieuwpoort with currents flowing southwestward in both spring and neap tides (Fig. 8E1 and E2). A large mesoscale structure dominates during spring and neap tides, mostly on the west and offshore part of the BCZ.

To summarize, the lowest plume extension is observed when strong SW winds dominate (pattern B typical for winter and, to a smaller extent, for spring and autumn), while the largest extension is obtained when typical stratified summer conditions are combined with dominant NE winds (pattern E).

Concerning the river discharge, although no exhaustive sensitivity analysis has been conducted, we did not observe a clear influence of Scheldt and Rhine discharge intensity on the plume extension, which is in agreement with Lacroix et al. (2004). For instance, case D has a plume extension slightly higher than the average and case $B$ has it much smaller than the average; however in case D the discharge is twice smaller than in case B.

It should be noted, that the mapping to the main atmospheric patterns of the simulated hydrodynamics obtained in the sensitivity experiment, where the daily barotropic current at the open boundaries are set to zero, are very similar to those described above. 
Table A.5

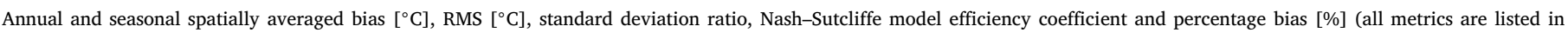

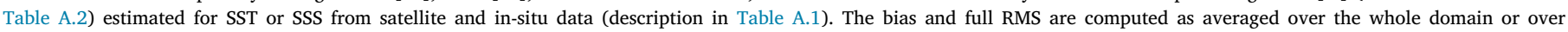
the HR domain for the CR and HR models. For in-situ data a point-to-point comparison is performed. " $\mathrm{n}$ " is the number of measurements.

\begin{tabular}{|c|c|c|c|c|c|c|c|c|}
\hline Variable & Dataset & Domain / Model & & Annual & Winter & Spring & Summer & Autumn \\
\hline \multirow{12}{*}{ SST } & \multirow{12}{*}{ Satellite } & \multirow{4}{*}{$\begin{array}{l}\text { whole domain } \\
\text { (CR model) }\end{array}$} & Bias & 0.4 & 0.01 & 0.47 & 0.88 & 0.23 \\
\hline & & & RMS & 0.77 & 0.48 & 0.73 & 1.07 & 0.56 \\
\hline & & & $\mathrm{PB}$ & 3.37 & 0.15 & 5.44 & 5.63 & 1.53 \\
\hline & & & NSME & 0.98 & 0.97 & 0.91 & 0.68 & 0.97 \\
\hline & & \multirow{4}{*}{$\begin{array}{l}\text { HR domain } \\
\text { (CR model) }\end{array}$} & Bias & 0.38 & -0.03 & 0.5 & 0.82 & 0.22 \\
\hline & & & RMS & 0.69 & 0.47 & 0.72 & 0.94 & 0.47 \\
\hline & & & PB & 3.1 & 0.3 & 5.52 & 4.99 & 1.45 \\
\hline & & & NSME & 0.98 & 0.98 & 0.92 & 0.73 & 0.98 \\
\hline & & \multirow{4}{*}{$\begin{array}{l}\text { HR domain } \\
\text { (HR model) }\end{array}$} & Bias & 0.37 & -0.1 & 0.48 & 0.86 & 0.21 \\
\hline & & & RMS & 0.72 & 0.49 & 0.72 & 0.98 & 0.5 \\
\hline & & & PB & 2.49 & 1.66 & 4.89 & 4.73 & 0.89 \\
\hline & & & NSME & 0.98 & 0.97 & 0.93 & 0.76 & 0.98 \\
\hline Variable & Dataset & Domain / Model & & Annual $(n=228)$ & Winter $(\mathrm{n}=73)$ & Spring $(n=55)$ & Summer $(n=77)$ & Autumn $(n=23)$ \\
\hline \multirow{8}{*}{ SST } & \multirow{8}{*}{ In-situ } & \multirow[t]{4}{*}{ CR model } & Bias & 0.43 & 0.04 & 0.69 & 0.71 & 0.1 \\
\hline & & & $\mathrm{PB}$ & 3.66 & 0.59 & 6.86 & 4.12 & 0.73 \\
\hline & & & RMS & 0.76 & 0.57 & 0.96 & 0.85 & 0.39 \\
\hline & & & Std ratio & 1.04 & 0.89 & 1.01 & 1.07 & 1.03 \\
\hline & & \multirow[t]{4}{*}{ HR model } & Bias & 0.43 & -0.15 & 0.65 & 0.96 & -0.03 \\
\hline & & & $\mathrm{PB}$ & 3.66 & 2.37 & 6.49 & 5.57 & 0.2 \\
\hline & & & RMS & 0.82 & 0.53 & 0.88 & 1.06 & 0.39 \\
\hline & & & Std ratio & 1.07 & 0.85 & 1.02 & 1.05 & 1.05 \\
\hline \multirow{8}{*}{ SSS } & \multirow{8}{*}{ In-situ } & \multirow[t]{4}{*}{ CR model } & Bias & 0.3 & 1.08 & -0.54 & -0.03 & 0.98 \\
\hline & & & PB & 0.92 & 3.3 & 1.67 & 0.1 & 3 \\
\hline & & & RMS & 1.45 & 1.62 & 1.81 & 0.87 & 1.46 \\
\hline & & & Std ratio & 1.22 & 1.03 & 1.13 & 1.13 & 1.37 \\
\hline & & \multirow[t]{4}{*}{ HR model } & Bias & -0.07 & 0.97 & -0.6 & -0.84 & 0.44 \\
\hline & & & PB & 0.23 & 2.98 & 1.87 & 2.54 & 1.36 \\
\hline & & & RMS & 1.54 & 1.6 & 1.93 & 1.29 & 1.03 \\
\hline & & & Std ratio & 1.13 & 0.97 & 1 & 1.07 & 1.27 \\
\hline
\end{tabular}

\subsection{Impact of spatial resolution on the simulated hydrodynamic variability}

In Section 4.3 (Fig. 4a and b), the comparison of the plume pattern simulated by the HR and CR models shows that the form of the frontal interface exhibits marked differences in the two simulations. The HR is able to simulate the non-linear dynamics of the haline front with the presence of well-defined oscillations while the CR simulates an almost straight frontal interface. In order to quantify this difference of variability between the two models, we demonstrate in this section how the model's spatial resolution affects its ability to depict the dynamic response to the different forcing regimes identified in Section 5.1. Fig. 9 illustrates the simulated plume and currents by the CR and HR models associated to pattern A for the spring tide.

While the $\mathrm{CR}$ model manages to reproduce correctly the general water direction for each pattern, it does not resolve the mesoscale structures depicted by the HR model, as illustrated for the pattern A for spring and neap tides (Fig. 9). To quantify the presence of mesoscale structures within each circulation pattern we averaged, in time and then over the HR domain, the relative vorticity of depth-averaged currents normalized by the planetary vorticity (named normalized relative vorticity hereafter). The normalized relative vorticity attained within HR simulations are about three times larger than that in the $\mathrm{CR}$ simulations, highlighting the more intense mesoscale activity within the BCZ.

More importantly, the HR model enables a clear distinction between hydrodynamics of the spring and neap tides that cannot be resolved with the CR model. The neap and spring patterns indeed form two distinct clusters in terms of normalized relative vorticity when considering the HR simulations (i.e. projecting the points of Fig. 10 on the vertical axis). This distinction cannot be done in the CR simulations (i.e. projecting Fig. 10 on the horizontal axis). The difference in the
Table A.6

Time share in $\%$ of each meteorological pattern in each season.

\begin{tabular}{llllll}
\hline \% of time & A & B & C & D & E \\
\hline Winter & 19.1 & 45 & 36.1 & 0 & 0 \\
\hline Spring & 23.4 & 20 & 19.7 & 9.5 & 27.3 \\
\hline Summer & 5.8 & 0 & 0 & 61.6 & 32.6 \\
\hline Autumn & 22.7 & 16.5 & 9.9 & 30.8 & 20.1 \\
\hline
\end{tabular}

circulation between the tidal phases is well illustrated for the pattern A, where the flow direction is completely different between the spring and neap tides (Fig. 9b and d). This change in direction is also resolved by the CR model (Fig. 9a and c). However, the change in terms of current intensity and turbulences is not as clear as in the HR case.

As for what the river plume is concerned, its region of influence can be depicted by the spatial distribution of the temporal standard deviation of SSS, which differs for the HR and CR simulations (Fig. 11). The region of plume activity depicted by the HR simulations is closer to the coast and highlights two branches that cannot be distinguished by the CR model. The enhanced consistency of the HR representation is supported by the standard deviation ratio between simulated and observed SSS at the LifeWatch stations 710 and 780, between these two branches, which are above 2 for the CR simulations, and closer to 1 and thus better represented by the HR model (Table A.4).

\section{Conclusion}

The ROMS model has been implemented to resolve the hydrodynamics in the SBNS with a focus on the BCZ. The BCZ is covered with a $1-\mathrm{km}$ grid model (HR) embedded through two-way nesting in a $5-\mathrm{km}$ 


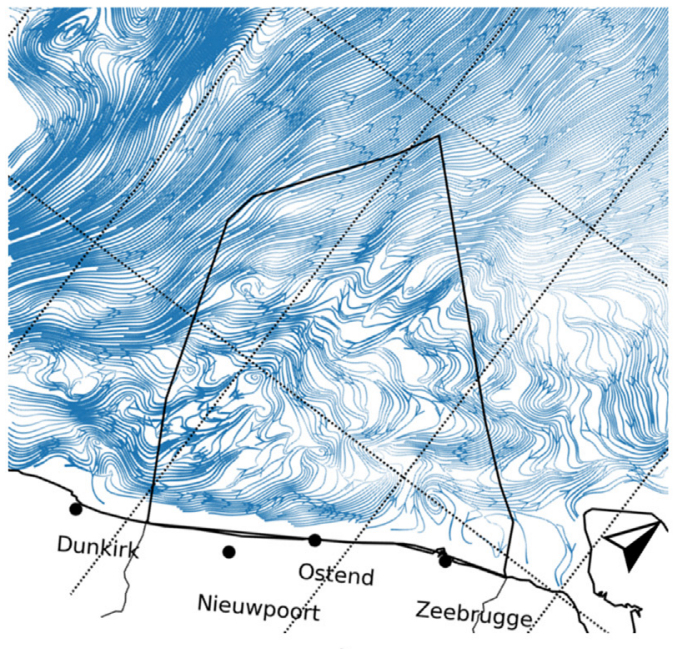

a)

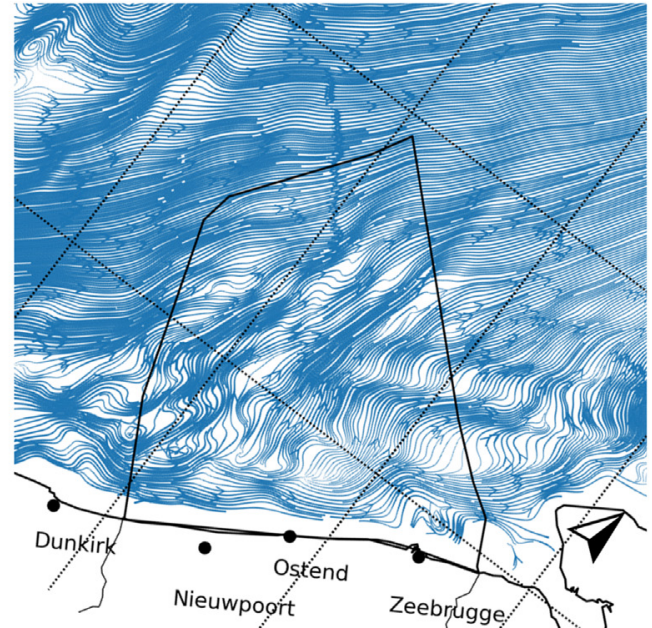

b)

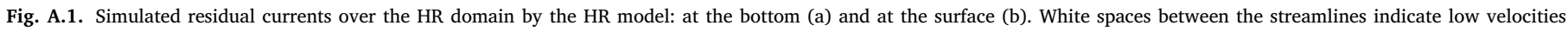
areas and areas where currents form a spiral indicate presence of eddies.
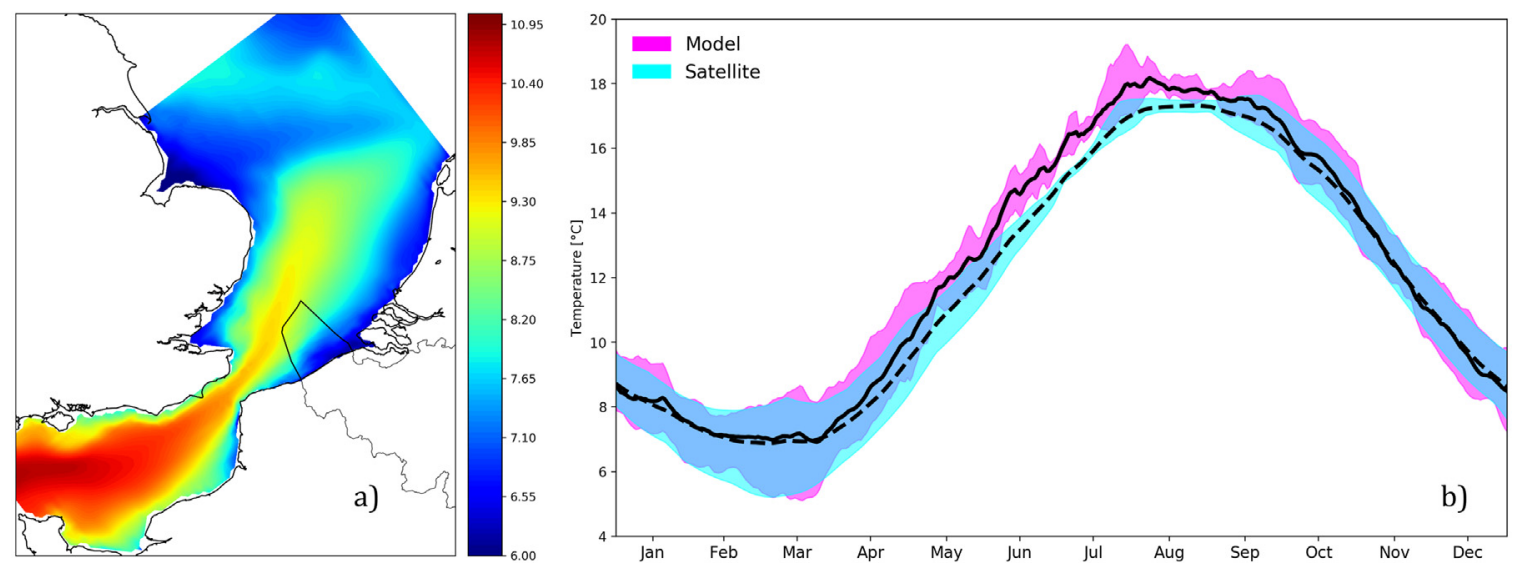

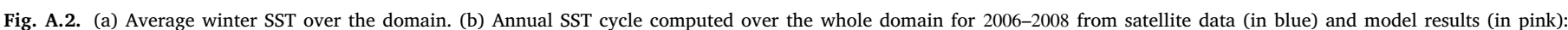

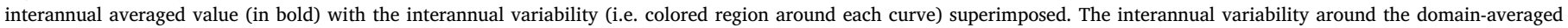
maximum and minimum values is quite limited to respectively $\pm 2{ }^{\circ} \mathrm{C}$ and $\pm 1{ }^{\circ} \mathrm{C}$.

model extending over the SBNS (CR). Here, we used this configuration to highlight the variability of circulation and plume dynamics in response to different tidal and atmospheric regimes. We then compared the capacity of both models to reproduce the main features of the BCZ hydrodynamics and its variability.

Model skill assessment was based on the literature survey, insitu LifeWatch and MeetNet networks, tidal gauges, and remote sensing. Overall, the model resolves well regional stratification, salinity and plume dynamics, residual circulation, tidal dynamics (phases, amplitudes and currents) as well as water transport through straits. It demonstrates excellent skills (Tables A.4 and A.5) in representing the SST annual cycle. Slightly poorer performances were obtained for the overtidal circulation (Table A.3).

The standard deviation analysis showed that the use of a HR model better resolves mesostructures of the Scheldt plume and increases its variability in response to the different atmospheric forcing. The most striking difference is demonstrated for residual currents, where the HR model is able to resolve mesoscale structures that are absent in the CR model. No major improvements were brought by the HR model as concerns overtidal components, which were expected to benefit from a high resolution. Also, model skill metrics derived from in-situ SST and SSS observations in the river plume area were not systematically enhanced for the HR model, and were sometimes slightly worse than for the CR model, in particular for RMS. We attributed this lack of significant improvement to enhanced frontal instabilities in the HR model, leading to stronger SSS and SST deviations which penalized the RMS metric in the expected case of imperfect spatiotemporal match of small scale features. This agrees with the conclusion of Stanev et al., 2016; Aguiar et al., 2020, and highlights that not only spatial resolution but also refinement of bathymetry, coastlines, estuarine dynamics and land influence on atmospheric forcings should be considered to really improve the accuracy of near-coastal dynamics. This also stresses the importance of embedding near-coastal monitoring frameworks in model development strategies (de Mey-Frémaux et al., 2019), for instance to enable assimilation procedures to enhance the correct localization of fine scale circulation features (e.g. HF radars).

The BCZ dynamic response to different atmospheric and tidal forcings displayed significant differences in terms of typical circulation and extension of the riverine plume. Dominant wind regimes have the potential to reverse the circulation over the BCZ in any season, with northeastern winds favoring southwestward current and extension of the river plume southward from Ostend, while strong southwestern winds create strong northeastward current with a significant reduction of the river plume extension within the BCZ. Also, mesoscale structures are more prone to develop during spring tides, while during neap tides the flow is usually laminar, which could support a more efficient 
offshore advection of nearshore suspended material. This distinction between the typical circulation regimes for spring and neap tides was very clear when using the HR model, and could not be resolved using the CR model. The HR grid also enabled a better delineation of the region of the riverine plume activity.

According to Fettweis and Van den Eynde (2003), the erosion of the seabed in the Belgian coastal area is for $10 \%$ driven by the waves, while the remaining is mainly due to tidal currents and wind action. A comprehensive simulation of SPM dynamics would thus require the coupling with the wave module and sediment bed dynamics. This will be the scope of a future study.

\section{CRediT authorship contribution statement}

Evgeny Ivanov: Methodology, Software, Validation, Formal analysis, Writing. Arthur Capet: Conceptualization, Methodology, Editing, Supervision. Alexander Barth: Editing, Supervision. Eric J.M. Delhez: Editing, Supervision. Karline Soetaert: Editing, Supervision. Marilaure Grégoire: Conceptualization, Methodology, Editing, Supervision, Funding acquisition.

\section{Declaration of competing interest}

The authors declare that they have no known competing financial interests or personal relationships that could have appeared to influence the work reported in this paper.

\section{Acknowledgments}

The authors thank the Belgian Federal Science Policy Office (BELSPO), Belgium for financing the current research in the frames of the BRAIN FaCE-iT project and the University of Liège for providing the needed infrastructure. Arthur Capet and Marilaure Grégoire are respectively postdoctoral fellow and research director from the Fonds de la Recherche Scientifique (FNRS). Computational resources have been provided by the Consortium des Équipements de Calcul Intensif (CÉCI), funded by the Fonds de la Recherche Scientifique de Belgique (F.R.S.FNRS) and the Wallonian Region under Grant No. 2.5020.11. This work was also supported by data and infrastructure provided by VLIZ as part of the Flemish contribution to LifeWatch and by the European Centre for Medium-Range Weather Forecasting (ECMWF). This study has also been conducted using E.U. Copernicus Marine Service Information.

\section{Appendix. Tables and figures}

See Figs. A.1 and A.2

\section{References}

Aguiar, E., Mourre, B., Juza, M., Reyes, E., Hernández-Lasheras, J., Cutolo, E., Mason, E., Tintoré, J., 2020. Multi-platform model assessment in the Western Mediterranean Sea: impact of downscaling on the surface circulation and mesoscale activity. Ocean Dyn. 70 (2), 273-288.

Allen, J.I., Holt, J.T., Blackford, J., Proctor, R., 2007a. Error quantification of a high-resolution coupled hydrodynamic-ecosystem coastal-ocean model: Part 2. Chlorophyll-a, nutrients and SPM. J. Mar. Syst. 68 (3-4), 381-404.

Allen, J.I., Somerfield, P.J., Gilbert, F.J., 2007b. Quantifying uncertainty in highresolution coupled hydrodynamic-ecosystem models. J. Mar. Syst. 64 (1-4), $3-14$.

Arndt, S., Lacroix, G., Gypens, N., Regnier, P., Lancelot, C., 2011. Nutrient dynamics and phytoplankton development along an estuary-coastal zone continuum: a model study. J. Mar. Syst. 84 (3-4), 49-66.

Barth, A., Alvera-Azcárate, A., Weisberg, R.H., 2008a. Benefit of nesting a regional model into a large-scale ocean model instead of climatology. Application to the West Florida Shelf. Cont. Shelf Res. 28 (4-5), 561-573.

Barth, A., Alvera-Azcárate, A., Weisberg, R.H., 2008b. A nested model study of the Loop Current generated variability and its impact on the West Florida Shelf. J. Geophys. Res.: Oceans 113 (C5).

Breton, S.P., Moe, G., 2009. Status, plans and technologies for offshore wind turbines in Europe and North America. Renew. Energy 34 (3), 646-654.
Capet, A., Barth, A., Beckers, J.M., Marilaure, G., 2012. Interannual variability of Black Sea's hydrodynamics and connection to atmospheric patterns. Deep Sea Res. Part II: Top. Stud. Oceanogr. 77, 128-142.

Costanza, R., Andrade, F., Antunes, P., van den Belt, M., Boesch, D., Boersma, D., Catarino, F., Hanna, S., Limburg, K., Low, B., et al., 1999. Ecological economics and sustainable governance of the oceans. Ecol. Econ. 31 (2), 171-187.

Davies, A., Furnes, G., 1980. Observed and computed M2 tidal currents in the North Sea. J. Phys. Oceanogr. 10 (2), 237-257.

De Brye, B., de Brauwere, A., Gourgue, O., Kärnä, T., Lambrechts, J., Comblen, R., Deleersnijder, E., 2010. A finite-element, multi-scale model of the Scheldt tributaries, river, estuary and ROFI. Coast. Eng. 57 (9), 850-863.

De Mesel, I., Kerckhof, F., Norro, A., Rumes, B., Degraer, S., 2015. Succession and seasonal dynamics of the epifauna community on offshore wind farm foundations and their role as stepping stones for non-indigenous species. Hydrobiologia 756 (1), 37-50.

De Mesel, I., Kerckhof, F., Rumes, B., Norro, A., Houziaux, J.S., Degraer, S., 2013. In: Degraer, S., Brabant, R., Rumes, B. (Eds.), Fouling Community on the Foundations of Wind Turbines and the Surrounding Scour Protection.

de Mey-Frémaux, P., Ayoub, N., Barth, A., Brewin, R., Charria, G., Campuzano, F., Ciavatta, S., Cirano, M., Edwards, C.A., Federico, I., et al., 2019. Model-observations synergy in the coastal ocean. Front. Mar. Sci.

Debreu, L., Marchesiello, P., Penven, P., Cambon, G., 2012. Two-way nesting in splitexplicit ocean models: algorithms, implementation and validation. Ocean Model. 49, 1-21.

Degraer, S., Brabant, R., Rumes, B., Vigin, L., 2018. Environmental Impacts of Offshore Wind Farms in the Belgian Part of the North Sea: Assessing and Managing Effect Spheres of Influence. Royal Belgian Institute of Natural Sciences, OD Natural Environment, Marine.

Delhez, E., 1996. Reconnaissance of the general circulation of the North-Western European Continental Shelf by means of a three-dimensional turbulent closure model. Earth-Sci. Rev. 41 (1-2), 3-29.

Delhez, E., Carabin, G., 2001. Integrated modelling of the Belgian coastal zone. Estuar. Coast. Shelf Sci. 53 (4), 477-491.

Delhez, É.J., Damm, P., De Goede, E., De Kok, J., Dumas, F., Gerritsen, H., Jones, J., Ozer, J., Pohlmann, T., Rasch, P., et al., 2004. Variability of shelf-seas hydrodynamic models: lessons from the NOMADS2 project. J. Mar. Syst. 45 (1-2), 39-53.

Egbert, G.D., Erofeeva, S.Y., Ray, R.D., 2010. Assimilation of altimetry data for nonlinear shallow-water tides: Quarter-diurnal tides of the Northwest European Shelf. Cont. Shelf Res. 30 (6), 668-679.

Fairall, C., Bradley, E.F., Hare, J., Grachev, A., Edson, J., 2003. Bulk parameterization of air-sea fluxes: Updates and verification for the COARE algorithm. J. Clim. 16 (4), 571-591.

Fettweis, M., Van den Eynde, D., 2003. The mud deposits and the high turbidity in the Belgian-Dutch coastal zone, southern bight of the North Sea. Cont. Shelf Res. 23 (7), 669-691.

Flather, R., 1976. A tidal model of the north-west European continental shelf. Mem. Soc. R. Sci. Liege 10, 141-164.

Floeter, J., van Beusekom, J.E., Auch, D., Callies, U., Carpenter, J., Dudeck, T., Eberle, S., Eckhardt, A., Gloe, D., Hänselmann, K., et al., 2017. Pelagic effects of offshore wind farm foundations in the stratified North Sea. Prog. Oceanogr. 156, 154-173.

Haidvogel, D.B., Arango, H.G., Hedstrom, K., Beckmann, A., Malanotte-Rizzoli, P., Shchepetkin, A.F., 2000. Model evaluation experiments in the North Atlantic Basin: simulations in nonlinear terrain-following coordinates. Dyn. Atmos. Oceans 32 (3-4), 239-281.

Hashemi, M.R., Neill, S.P., Davies, A.G., 2015. A coupled tide-wave model for the NW European shelf seas. Geophys. Astrophys. Fluid Dynam. 109 (3), 234-253.

Holt, J.T., Allen, J.I., Proctor, R., Gilbert, F., 2005. Error quantification of a highresolution coupled hydrodynamic-ecosystem coastal-ocean model: Part 1 model overview and assessment of the hydrodynamics. J. Mar. Syst. 57 (1-2), 167-188.

IOC, I., 2003. BODC: Centenary Edition of the GEBCO Digital Atlas. British Oceanographic Data Centre, Liverpool, UK, published on CD-ROM on behalf of the Intergovernmental Oceanographic Commission and the International Hydrographic Organization as part of the General Bathymetric Chart of the Oceans.

Kaldellis, J., Kapsali, M., 2013. Shifting towards offshore wind energy—Recent activity and future development. Energy Policy 53, 136-148.

Ketchen, D.J., Shook, C.L., 1996. The application of cluster analysis in strategic management research: an analysis and critique. Strateg. Manag. J. 17 (6), 441-458.

Kohonen, T., 1982. Self-organized formation of topologically correct feature maps. Biol. Cybern. 43 (1), 59-69.

Lacroix, G., Ruddick, K., Ozer, J., Lancelot, C., 2004. Modelling the impact of the Scheldt and Rhine/Meuse plumes on the salinity distribution in Belgian waters (southern North Sea). J. Sea Res. 52 (3), 149-163.

Lacroix, G., Ruddick, K., Park, Y., Gypens, N., Lancelot, C., 2007. Validation of the 3D biogeochemical model MIRO\&CO with field nutrient and phytoplankton data and MERIS-derived surface chlorophyll a images. J. Mar. Syst. 64 (1-4), 66-88.

Laevastu, T., 1963. Surface water types of the North Sea and their characteristics.

Le Provost, C., 1991. Generation of overtides and compound tides. Tidal Hydrodyn. 269-295. 
Lindström, G., Pers, C., Rosberg, J., Strömqvist, J., Arheimer, B., 2010. Development and testing of the HYPE (Hydrological Predictions for the Environment) water quality model for different spatial scales. Hydrol. Res. 41 (3-4), 295-319.

Los, F., Villars, M., Van der Tol, M., 2008. A 3-dimensional primary production model (BLOOM/GEM) and its applications to the (southern) North Sea (coupled physical-chemical-ecological model). J. Mar. Syst. 74 (1-2), 259-294.

Luyten, P.J., Jones, J.E., Proctor, R., 2003. A numerical study of the long-and shortterm temperature variability and thermal circulation in the North Sea. J. Phys. Oceanogr. 33 (1), 37-56.

Marchesiello, P., McWilliams, J.C., Shchepetkin, A., 2001. Open boundary conditions for long-term integration of regional oceanic models. Ocean Modell. 3 (1-2), 1-20.

Martinho, A.S., Batteen, M.L., 2006. On reducing the slope parameter in terrain-following numerical ocean models. Ocean Model. 13 (2), 166-175.

Mercier, C., Delhez, E., 2007. Diagnosis of the sediment transport in the Belgian Coastal Zone. Estuar. Coast. Shelf Sci. 74 (4), 670-683.

Moll, A., Radach, G., 2003. Review of three-dimensional ecological modelling related to the North Sea shelf system: Part 1: models and their results. Prog. Oceanogr. 57 (2), 175-217.

Pätsch, J., Burchard, H., Dieterich, C., Gräwe, U., Gröger, M., Mathis, M., Kapitza, H., Bersch, M., Moll, A., Pohlmann, T., et al., 2017. An evaluation of the North Sea circulation in global and regional models relevant for ecosystem simulations. Ocean Model. 116, 70-95.

Paulson, C.A., Simpson, J.J., 1977. Irradiance measurements in the upper ocean. J. Phys. Oceanogr. 7 (6), 952-956.

Pohlmann, T., 2006. A meso-scale model of the central and southern North Sea: consequences of an improved resolution. Cont. Shelf Res. 26 (19), 2367-2385.

Prandle, D., 1980. Co-tidal charts for the southern North Sea. Dtsch. Hydrografische Z. 33 (2), 68-81.

Richardson, A., Risien, C., Shillington, F., 2003. Using self-organizing maps to identify patterns in satellite imagery. Prog. Oceanogr. 59 (2-3), 223-239.

Salomon, J., Breton, M., Guegueniat, P., 1993. Computed residual flow-through the dover strait. Oceanol. Acta 16 (5-6), 449-455.

Shchepetkin, A.F., McWilliams, J.C., 2005. The regional oceanic modeling system (ROMS): a split-explicit, free-surface, topography-following-coordinate oceanic model. Ocean Modell. 9 (4), 347-404.

Slavik, K., Lemmen, C., Zhang, W., Kerimoglu, O., Klingbeil, K., Wirtz, K.W., 2018. The large-scale impact of offshore wind farm structures on pelagic primary productivity in the southern North Sea. Hydrobiologia 1-19.
Smolarkiewicz, P.K., Margolin, L.G., 1998. MPDATA: A finite-difference solver for geophysical flows. J. Comput. Phys. 140 (2), 459-480.

Stanev, E.V., Al-Nadhairi, R., Staneva, J., Schulz-Stellenfleth, J., Valle-Levinson, A., 2014. Tidal wave transformations in the German Bight. Ocean Dyn. 64 (7), 951-968.

Stanev, E.V., Schulz-Stellenfleth, J., Staneva, J., Grayek, S., Grashorn, S., Behrens, A., Koch, W., Pein, J., 2016. Ocean forecasting for the German Bight: from regional to coastal scales. Ocean Sci. 12 (5), 1105.

Sündermann, J., Pohlmann, T., 2011. A brief analysis of North Sea physics. Oceanologia 53 (3), 663-689.

Urrego-Blanco, J., Sheng, J., Dupont, F., 2016. Performance of one-way and two-way nesting techniques using the shelf circulation modelling system for the eastern canadian shelf. Atmos.-Ocean 54 (1), 75-92.

Van den Eynde, D., Baeye, M., Brabant, R., Fettweis, M., Francken, F., Haerens, P., Mathys, M., Sas, M., Van Lancker, V., 2013. All quiet on the sea bottom front? Lessons from the morphodynamic monitoring. In: Offshore Wind Farms in the Belgian part of the North Sea: Heading for an Understanding of Environmental Impacts, Vol. 3547. Royal Belgian Institute of Natural Sciences, Management Unit of the North Sea Mathematical Models, Marine Ecosystem Management Unit, Brussels.

Van der Molen, J., Smith, H.C., Lepper, P., Limpenny, S., Rees, J., 2014. Predicting the large-scale consequences of offshore wind turbine array development on a North Sea ecosystem. Cont. Shelf Res. 85, 60-72.

Wakelin, S., While, J., King, R., O’Dea, E., Holt, J., Furner, R., Siddorn, J., Martin, M., McEwan, R., Blockley, E., et al., 2015. Quality information document: North West European shelf reanalysis northwestshelf_reanalysis_phys_004_009 and northwestshelf_reanalysis_bio_004_011. EU Copernicus Marine Service.

Warner, J.C., Armstrong, B., He, R., Zambon, J.B., 2010. Development of a coupled ocean-atmosphere-wave-sediment transport (COAWST) modeling system. Ocean Modell. 35 (3), 230-244.

Warner, J.C., Defne, Z., Haas, K., Arango, H.G., 2013. A wetting and drying scheme for ROMS. Comput. Geosci. 58, 54-61.

Warner, J.C., Sherwood, C.R., Arango, H.G., Signell, R.P., 2005. Performance of four turbulence closure models implemented using a generic length scale method. Ocean Model. 8 (1-2), 81-113. 